\title{
Multiplicity of acquired cross-resistance in paclitaxel-resistant cancer cells is associated with feedback control of TUBB3 via FOX03a-mediated ABCB1 regulation
}

\author{
Mark Borris D. Aldonza ${ }^{1,2,4}$, Ji-Young Hong ${ }^{1}$, Malona V. Alinsug ${ }^{3}$, Jayoung Song ${ }^{1}$, \\ Sang Kook Lee ${ }^{1}$ \\ ${ }^{1}$ College of Pharmacy, Seoul National University, Seoul 151-742, Korea \\ ${ }^{2}$ Department of Biochemistry, College of Veterinary Medicine, Seoul National University, Seoul 151-742, Korea \\ ${ }^{3}$ Center for Food and Bioconvergence, College of Agriculture and Life Sciences, Seoul National University, Seoul 151-742, \\ Korea \\ ${ }^{4}$ Present address: Department of Biological Sciences, Korea Advanced Institute of Science and Technology (KAIST), Daejeon \\ 305-701, Korea
}

Correspondence to: Sang Kook Lee, email: sklee61@snu.ac.kr

Keywords: paclitaxel resistance, multidrug resistance, FOXO3a, TUBB3, ABCB1

Received: February 17, $2016 \quad$ Accepted: April 11, $2016 \quad$ Published: April 30, 2016

\section{ABSTRACT}

Acquired drug resistance is a primary obstacle for effective cancer therapy. The correlation of point mutations in class III $\beta$-tubulin (TUBB3) and the prominent overexpression of ATP-binding cassette P-glycoprotein (ABCB1), a multidrug resistance gene, have been protruding mechanisms of resistance to microtubule disruptors such as paclitaxel (PTX) for many cancers. However, the precise underlying mechanism of the rapid onset of cross-resistance to an array of structurally and functionally unrelated drugs in PTX-resistant cancers has been poorly understood. We determined that our established PTX-resistant cancer cells display $A B C B 1 / A B C C 1$-associated cross-resistance to chemically different drugs such as 5-fluorouracil, docetaxel, and cisplatin. We found that feedback activation of TUBB3 can be triggered through the FOXO3a-dependent regulation of $A B C B 1$, which resulted in the accentuation of induced PTX resistance and encouraged multiplicity in acquired cross-resistance. FOXO3a-directed regulation of P-glycoprotein (P-gp) function suggests that control of $A B C B 1$ involves methylation-dependent activation. Consistently, transcriptional overexpression or downregulation of FOXO3a directs inhibitor-controlled proteasedegradation of TUBB3. The functional PI3K/Akt signaling is tightly responsive to FOХОЗ activation alongside doxorubicin treatment, which directs FOXO3a arginine hypermethylation. In addition, we found that secretome factors from PTX-resistant cancer cells with acquired cross-resistance support a P-gp-dependent association in multidrug resistance (MDR) development, which assisted the FOXO3a-mediated control of TUBB3 feedback. The direct silencing of TUBB3 reverses induced multiple cross-resistance, reduces drug-resistant tumor mass, and suppresses the impaired microtubule stability status of PTX-resistant cells with transient cross-resistance. These findings highlight the control of the TUBB3 response to ABCB1 genetic suppressors as a mechanism to reverse the profuse development of multidrug resistance in cancer.

\section{INTRODUCTION}

Multidrug resistance (MDR) in cancer is a phenomenal limitation to the success of chemotherapy in which cancer cells gain the capacity to develop crossresistance to a broad range of structurally and functionally unrelated drugs. Among the well-known mechanisms underlying MDR is the hyperactivity of drug efflux by 
ATP-binding cassette (ABC) transporters bound in the cell membrane compartments. The overexpression of $\mathrm{ABC}$ transcription correlates with an increase in patient relapse during or following treatment with various chemotherapy drugs $[1,2]$. Paclitaxel (PTX), an anticancer drug against various human solid tumors, primarily targets microtubules (mt) to disrupt mitosis, motility, and the growth of cells. PTX-resistant cancers highlight the rapid onset of multiple cross-resistance and the high percentage of failures even in therapies that involve drug combinations. Alterations in tubulin-isoform expression alongside the overexpression of energy-driven P-glycoprotein (P-gp; encoded by $A B C B 1$ ) are well-known causative factors of taxane-refractory tumors. Mt-targeting agents such as PTX and its synthetic analogue docetaxel (DCT) bind to the $\beta$-subunit in the $\alpha \beta$-tubulin dimer, which exemplifies the stability of the mt assembly $[3,4]$. In several cancers, class III $\beta$-tubulin (encoded by $T U B B 3$ ) is a predictive biomarker of clinical PTX resistance and a DCT-based chemotherapy response [5]. A number of factors are involved in the concession of mt-targeted therapies including the patient's $\beta$-tubulin isotype differential expression profile in various tissues/ organs and the modifications in tubulin-binding sites, $\mathrm{mt}$ assembly properties, tubulin synthesis, and tubulin polymerization. Dynamic equilibrium between soluble tubulin dimers are maintained by microtubule-associated proteins (MAPs) collectively known as microtubule inner proteins (MIPs), which include proteins that are intact with tubulin heterodimers. This specific occasion of equipoise is often targeted by PTX but is altered in several malignancies $[6,7]$. Conflicting results and inconsistencies have previously been identified in both in vitro and in vivo models of the mechanism of MAPs in drug resistance, which suggests that there is much work remaining to elucidate the precise mechanisms of action.

A rapidly growing paradigm is that targeted therapies require factors that can overcome the spontaneous mutations in $\beta$-tubulin isotypes to reverse resistance to PTX and other taxanes [8]. Therefore, designing small molecule drugs and testing rationale drug combinations that can target specific $\beta$-tubulin isotype modifications to reverse P-gp-mediated resistance are warranted; however, this is very challenging because structurally, the seven isotypes of $\beta$-tubulin have complex differential functional mechanisms on $\mathrm{mt}$ and play key roles in cellular homeostasis [9]. Therefore, the discovery of genes that can regulate the feedback control of $\beta$-tubulin isotypes associated with drug sensitivity is necessary to provide a rationale platform for both MDR biomarkers and therapeutic discoveries.

Forkhead box class $\mathrm{O}$ (FOXO) transcription factors such as $F O X O 3 a$ have recently been identified as key players in the initiation of cancer and the development of drug resistance. The anticancer drug-mediated up-regulation of $F O X O 3 a$ enhances $A B C B 1$ expression, which may directly contribute to the genesis of MDR in general and to the implicated $F O X O$ activation-mediated chemotherapy response, including those cytostatic and cytotoxic effects amended by PTX, DCT, cisplatin (CIS), gefitinib (GEF), and 5-fluorouracil (5-FU) [10, 11]. Identified as downstream targets of the PI3K/Akt pathway, FOXO transcription factors are associated with tumorigenesis and chemotherapeutic resistance in several ways, such as through inhibiting the transactivation of drug-target genes (e.g., p27/Kip1, Bcl$\mathrm{xL}$, cyclin $\mathrm{D}$, and Bim) involved in cell proliferation, apoptosis, and differentiation [12]. In addition, because the overexpression of Akt can increase resistance to PTX, FOXO transcription factors have since been implicated in determining drug sensitivity and affecting other signal transduction pathways that regulate the response to PTX. Similarly, the MAPK member JNK, specifically its submembers JNK1 and JNK2, augment protection from the toxic effects of PTX $[13,14]$. Furthermore, PTX not only induces FOXO3a expression but also enhances its nuclear translocation through a JNK-dependent mechanism and affects its ubiquitin-mediated degradation. Meanwhile, FOXO3a, aside from affecting PTX actions, regulates the DNA damage response and stimulates the DNA repair pathway, which regulates the sensitivity to drugs that target the DNA repair system such as 5-FU and CIS, among others $[15,16]$. Forkhead box M1 (FOXM1) and FOXO3a have been observed to compete in binding to similar DNA sequences, which often results in antagonized transcriptional output that has recently been related to genotoxic drug resistance and the response of various cancers to chemotherapy $[17,18]$.

Considerable progress has been made in determining the mechanism of FOXO-regulated mt organization. Very recently, FOXO has also been implicated in drug-mediated cytoskeletal stress because of its effects on neuronal $\mathrm{mt}$ organization following pharmacological damage, which requires Akt kinase [19, 20]. Importantly, some FOXO transcription factors also influence the PTX-induced inhibition of the androgen receptor (AR), suggesting a connection between the mt-dependent trafficking of the AR and the clinical efficacy of PTX as well as that of other taxanes [21]. Although these distinct drug-induced $\mathrm{mt}$ organization regulatory events may suggest a connection between $\beta$-tubulin isotypes such as TUBB3 and FOXO transcription factors, very little is known about the systemic relation of these factors and their collective function as interacting elements in the regulation of the response of cancers to chemotherapeutic drugs and the malignant progression of tumors caused by MDR that often leads to cancer recurrence.

Herein, in light of the increasing demand to uncover drug resistance mechanisms, we dissected the function of $F O X O 3 a$-mediated $A B C B 1$ in regulating $T U B B 3$ feedback in the context of the development of multiple cross-resistance to chemically unrelated cancer chemotherapeutics in PTX-resistant cancer cells, and we extended this event to systemic drug-resistant tumor progression. 


\section{RESULTS}

\section{$A B C B 1$-associated acquired drug resistance is correlated with $T U B B 3$ and $F O X O 3 a$ expression}

Given the previous reports that separately associate drug-induced FOXO3a phosphorylation and TUBB3 alterations with the overexpression of $A B C B 1$ [5, 11], we sought to examine the transcription and protein expression patterns of TUBB3 and FOXO3a in a panel of non-tumor (normal cell), drug-sensitive cancer, and drug-resistant cancer cell models to correlate their expression with MDR development. A gene expression analysis showed that both TUBB3 and FOXO3a mRNA levels are relatively lower in non-cancer RWPE-1 prostate cells, L132 and MRC-5 lung cells, and HEK293 and HUVEC cells whereas their levels are higher in drug-sensitive cancer PC-3 prostate

A
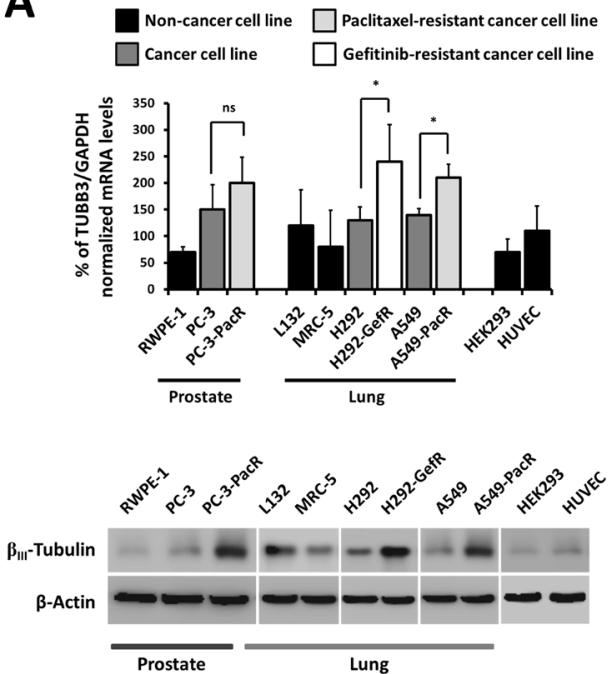

C

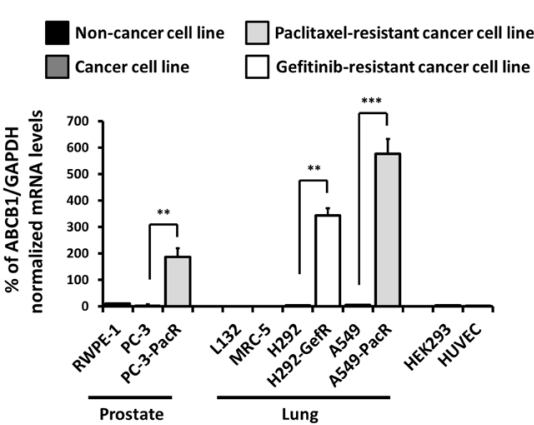

cells and $\mathrm{H} 292$ and A549 lung cells. The expressions of both TUBB3 and FOXO3a were the highest in cancer cells with derived PTX and GEF resistance. In PacR cancer cells, TUBB 3 expression had $>2.8$ and $>1.3$ fold increases while FOXO3a had $>2.8$ and $>1.0$ fold increases when compared to both drug-sensitive normal and cancer cells, respectively. A Western blot analysis also exhibited the same expression patterns of both genes including FOXO3a phosphorylation (Figure 1A, 1B), which showed relatively higher expressions in drug-resistant variants. Furthermore, the level of $A B C B 1$ gene expression was confirmed to be several-fold higher in drug-resistant cancer cells compared to normal and parental cells, which confirms the high level of drug resistance in these cells (Figure 1C). Higher P-gp expression in drugresistant cancer cells compared to their parent cells was clearly demonstrated both in protein expression (Figure 1D) and intracellular distribution (Figure 1E).
B
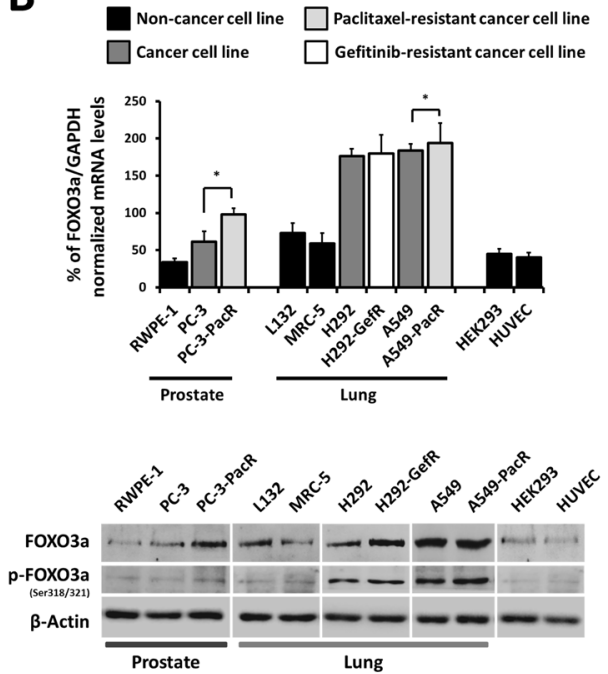

D

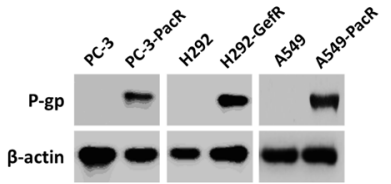

$\mathbf{E}$

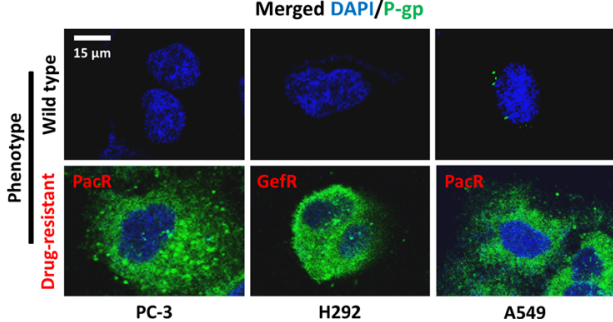

Figure 1: Overexpression profiles of TUBB3 and FOXO3a in a panel of cancer cells with ABCB1-associated acquired drug resistance. (A) Characterization of indicated parental or drug-resistant phenotype cell lines for TUBB3 expression at both mRNA (upper panel) and protein (lower panel) levels. (B) Characterization of indicated parental or drug-resistant phenotype cell lines for FOXO3a expression at both mRNA (upper panel) and protein (lower panel) levels. (C) Identification of $A B C B 1$-association expression in a panel of indicated parental or drug resistant cancer cell lines at the mRNA level. (D) Confirmation of P-gp protein overexpression in drug resistant cancer cell lines. (E) Intracellular distribution and localization of P-gp expression in both wild-type and drug-resistant phenotype cell lines. Cells were stained with human P-gp antibody and DAPI and analyzed through confocal microscopy. Images shown were magnified at $\times 200$. 


\section{PTX-resistant cancer cells display frequent cross-resistance to DCT, 5-FU, and CIS associated with high P-gp-mediated drug efflux}

Several paclitaxel-resistant cancers have been defined to have cross-resistance to a variety of chemically unrelated drugs such as cisplatin, vinblastine, and anthracyclines $[22,23]$. Along with the overexpression of P-gp $(A B C B 1)$, progress in determining other key molecular events that lead to the onset of multiple cross-resistance in PTXresistant cancers has been greatly hampered [24]. To investigate the degree and mechanism of cross-resistance in PTX-resistant cancer cells, we employed our previously established PTX-resistant sublines, A549-PacR and PC3-PacR cells, and developed transient cross-resistance to 5-FU, DCT, and CIS (see the Experimental Procedures). First, we identified whether P-gp drug efflux is involved in the occurrence of cross-resistance to 5-FU, DCT, and CIS in PTX-resistant cancer cells. Notably, fractions of the drug intolerant cells following treatment with apoptosisinducing concentrations of the drugs were increased in PTX-resistant cancer cells and $A B C B 1$-transfected HEK293 cells, suggesting that $\mathrm{P}$-gp expression is highly correlated, except to CIS cross-resistance (Figure 2A, 2B). The number of drug-resistant colonies following exposure to 5-FU-conditioned media (CM) complemented these findings (Figure 2C). A549-PacR and HEK293/ABCB1 cells showed very low intracellular accumulation of Rho-123 dye relative to parental and empty vector (EV)transfected cells (Figure 2D). Paclitaxel resistant (PacR) cells displayed lower ABCB1 ATPase activity following DCT and 5-FU treatment compared to DMSO (vehicle)treated control cells, whereas HEK293/ABCB1 cells induced minimal lowered levels (Figure 2E). Treatment with 5-FU, DCT, and CIS positively stimulated P-gp protein expression in A549-PacR and PC-3-PacR cells (Figure 2F). Moreover, a lower 5-FU concentration regulated $A B C B 1$ gene expression in A549-PacR and PC3-PacR cells in a strict time-dependent manner whereas variations in $A B C B 1$ gene expression were observed in HEK293/ABCB1 cells (Figure 2G). Drug-stimulated P-gpspecific luminescent ATPase activity of both A549-PacR and PC-3-PacR cells was stimulated in a concentrationdependent manner following 5-FU treatment (Figure 2H). The cells were then screened for their response to a variety of chemotherapeutics. Both A549-PacR and PC-3-PacR cells were found to have frequent cross-resistance to DCT, 5-FU, and CIS whereas H292-GefR cells had minimalfold cross-resistance, as determined by the $\mathrm{IC}_{50}$ values of incorporated drugs (Table 1). In addition, PacR cancer cells with developed transient cross-resistance showed increased resistance relative to both the parental and PacR cells in all of the drug cases tested. Specifically, PacR cancer cells with transient 5-FU cross-resistance (-PacR/5-FU) showed the highest relative resistance and P-gp dependence among others with distinct MRP ( $A B C C 1)$ overexpression in the PC-3 subline, as determined by Western blot analysis. $A B C B 1$-transfected HEK293 cells also displayed crossresistance to 5-FU and DCT but not to CIS. These results suggest the involvement of P-gp activity in multiple crossresistance in PTX-resistant cancer cells.

\section{Multiple cross-resistance in PTX-resistant cancer cells involves regulated $T U B B 3$ and $F O X O 3 a$ expressions and supports escape from drug- induced apoptosis}

The overexpression of TUBB3 has been clinically implicated in several malignancies with PTX-resistance [25]; this mechanism appears to be dependent on tubulinmutation-induced decreases in mt stability [26]. Meanwhile, an $A k t$-dependent increase of $F O X O 3 a$ activity was observed in response to PTX-induced apoptosis and was correlated with limited mt stability conferring $A B C B 1$-associated drug resistance $[15,27,28]$. To study the potential phenomenon of TUBB3 and FOXO3a regulation in the context of PTXresistance and MDR in cancer cells, PTX-resistant cells with developed transient cross-resistance were analyzed (Figure 3A). Late-passage (p\#21) cells were subjected to 5-FU treatment, which showed the growth inhibition in A549 parental cells in a concentration-dependent manner whereas A549-PacR cells with developed transient cross-resistance to 5-FU, DCT, and CIS displayed continued resistance even at a high concentration treatment with a higher fraction of cells surviving than just A549-PacR cells (Figure 3B). To associate this sustained cross-resistance with P-gp, $A B C B 1$ mRNA levels were determined in late-passage A549-PacR/5-FU and PC-3-PacR/5-FU cells while being maintained with very low concentrations of 5-FU overtime. The cells were harvested at days $0,5,10$, and 15 subsequent to cell passage (reaching p\#12-14) and subculture processes after generation and were analyzed for target gene expression. We found significantly increased levels of $A B C B 1$ over time (relative to day 0 ) that were sustained even at day 15 in both cells. Sustained transient crossresistance to 5-FU in PTX-resistant cells appeared to involve $A B C C 1$ because the gene levels were slightly increased over time (Figure 3C). TUBB3 and $F O X O 3 a$ gene levels were significantly increased in A549-PacR/5-FU, A549-PacR-/ DCT (Figure 3D), PC-3-PacR/5-FU, and PC-3-PacR-/DCT (Figure 3E) cells compared to the PacR phenotype only and were slightly regulated, although an increase was detectable, in HEK293/ABCB1 cells compared to EV-transfected cells (Figure 3F). To confirm that the qRT-PCR data were correlated with increased protein levels, the expressions of $\beta_{\mathrm{III}}$-tubulin, phosphorylated FOXO3a, and P-gp were determined. Consistent with the findings of gene expression, the expressions of $\beta_{\mathrm{III}}$-tubulin and phosphorylated FOXO3a were up-regulated in 5-FU and DCT cross-resistant cells compared to the PacR phenotype only. In addition, all of 
the cells also exhibited continued P-gp expression (Figure 3G). In HEK293 cells, the establishment of transient crossresistance to 5-FU and DCT in the $A B C B 1$-overexpressing subline caused an activation of $\beta_{\mathrm{III}}$-tubulin compared to the minimally down-regulated levels in EV-transfected cells (Figure $3 \mathrm{H}$ ). These data suggest that TUBB3 and FOXO3a play significant roles in conferring cross-resistance in PTXresistant cancers associated with $A B C B 1$.

We observed that 5 -FU $(40 \mu \mathrm{M}$ in form of pretreatment) stimulated an escape from etoposide-induced apoptosis in A549-PacR cells (Supplementary Figure 1).
To functionally examine whether P-gp-associated crossresistance to 5-FU confers apoptosis protection, we employed the P-gp inhibitor, verapamil. A549-PacR/5-FU cells showed a reduced fraction of apoptotic cells compared to A549-PacR cells after treatment with an apoptosisinducing concentration of verapamil (Figure 3I). Of note, this effect was supported by the expression of apoptotic biomarkers. Verapamil down-regulated the expressions of both Bax and p53 and up-regulated the expression of Bcl-2 in A549-PacR/5-FU cells compared to A549-PacR cells (Figure 3J). A rapid increase in verapamil-induced

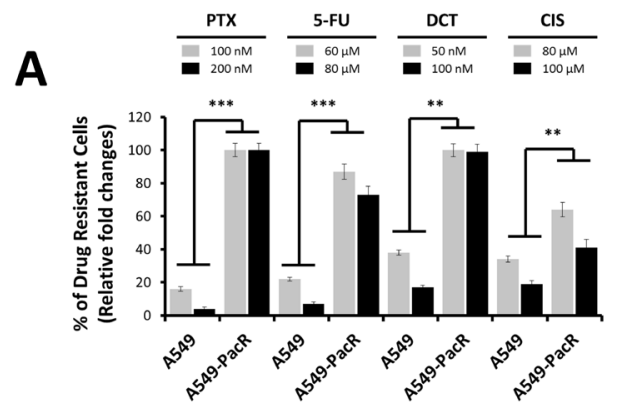

B
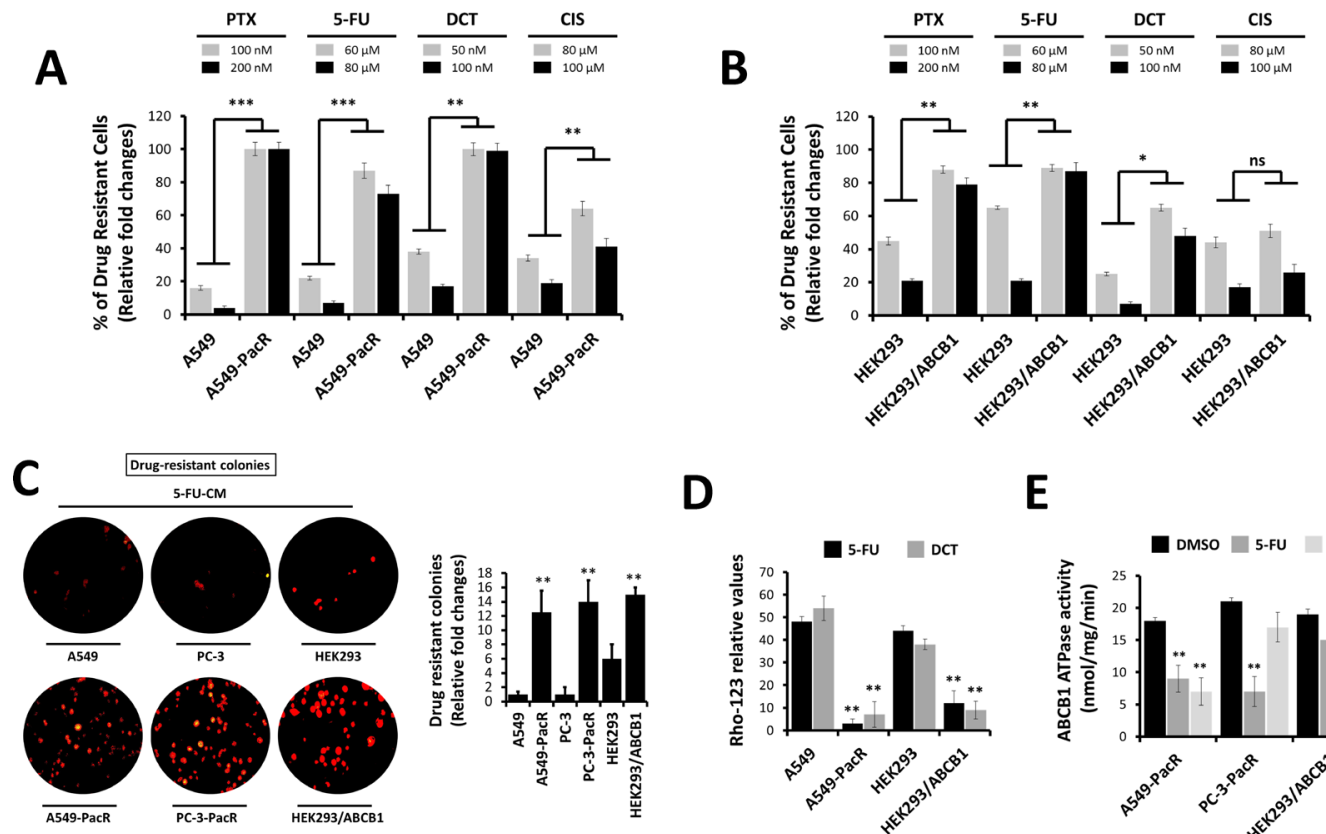

D
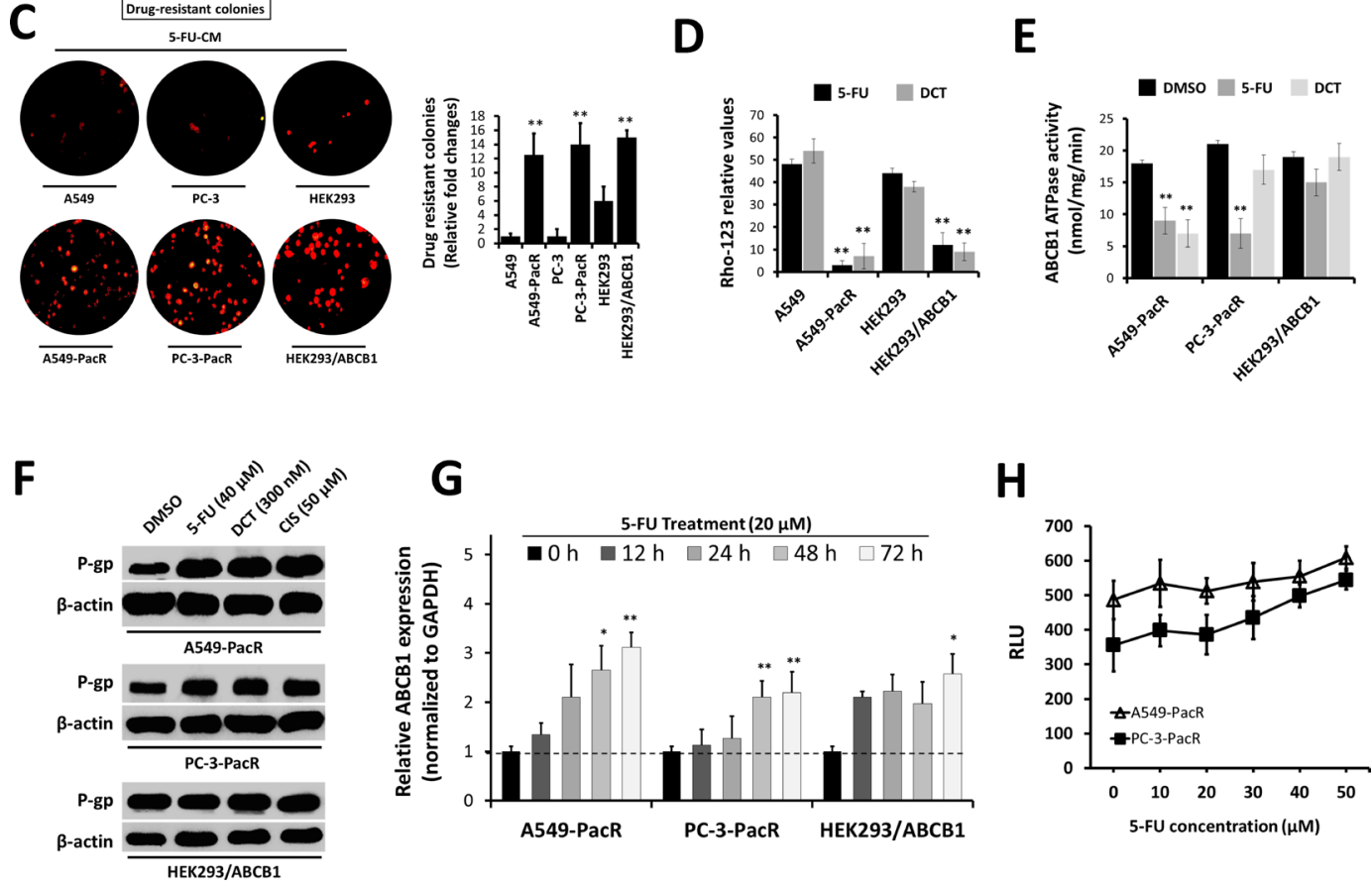

G

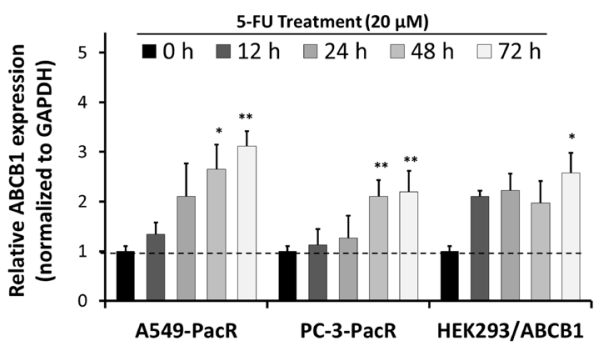

H

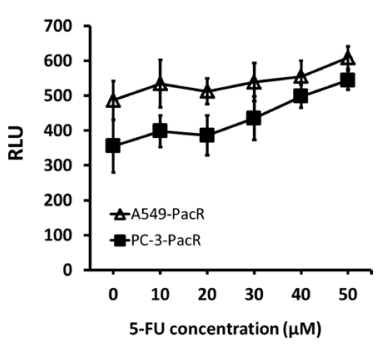

Figure 2: Occurrence of cross-resistance in PTX-resistant cancer cells is highly associated with ATP-dependent P-gp/ ABCB1 efflux activity. (A and B) Fraction of drug-intolerant A549, A549-PacR (A) and HEK293, HEK293/ABCB1 (B) cells. Cells were treated with PTX, 5-FU, DCT, or CIS for $24 \mathrm{hr}$, and the cell viability was determined by MTT assay. Data are represented as means \pm SEM. (C) Representative drug intolerant cell colonies (right) and quantified colony numbers of A549-PacR cells (left). Cells were exposed to 5-FU-conditioned media (CM) and continuously grown for $>7$ days and formed colonies of established PTX-resistant cells were stained with sapphire 700. Data are represented as means \pm SEM. (D and E) ATP-dependent P-gp efflux activity. Cells were treated with $60 \mu \mathrm{M}$ 5-FU for $24 \mathrm{hr}$ and assayed for Rho-123 incorporation. Flow cytometry was used to quantify Rho-123 fluorescence (D). Drug-resistant cells were treated with DMSO, $60 \mu \mathrm{M}$ 5-FU, or $50 \mu \mathrm{M}$ DCT for $24 \mathrm{hr}$ and was assayed for $A B C B 1$ ATPase activity (E). Data are represented as means \pm SEM. (F and G) Association of P-gp expression with occurrence of cross-resistance. Drug-resistant cells were treated with 5-FU, DCT, or CIS for $24 \mathrm{hr}(\mathrm{F})$ and time-dependently treated with 5-FU for $(\mathrm{G})$. Cells were treated with $20 \mu \mathrm{M}$ 5-FU then assayed for qRT-PCR using $A B C B 1$-specific primer. (H) P-gp-specific ATPase activity. Cells were treated with increasing 5-FU concentration for 24 hr and cells were subjected to P-gp luminescent ATPase assay. Data are represented as means $\pm \mathrm{SEM}$. 
Table 1: Cross-drug resistance profile of cells with resistance to paclitaxel or gefitinib, and of ABCB1 transiently transfected cells and association with P-gp and MRP protein expressions

\begin{tabular}{|c|c|c|c|c|c|c|c|c|c|c|c|c|}
\hline \multirow{2}{*}{$\begin{array}{l}\text { Phenotype } \\
\text { Descrip- } \\
\text { tion }\end{array}$} & \multirow{2}{*}{$\begin{array}{c}\text { Cell } \\
\text { Line ID }\end{array}$} & \multicolumn{2}{|c|}{$\begin{array}{l}\text { WB Grade } \\
\text { (Protein) }\end{array}$} & \multicolumn{3}{|c|}{ 5-Fluorouracil (5-FU) } & \multicolumn{3}{|c|}{ Docetaxel (DCT) } & \multicolumn{3}{|c|}{ Cisplatin (CIS) } \\
\hline & & $\begin{array}{c}\text { P-gp/ } \\
\text { ABCB1 }\end{array}$ & $\begin{array}{c}\text { MRP/ } \\
\text { ABCC1 }\end{array}$ & $\begin{array}{c}\mathrm{IC}_{50}(\mu \mathrm{M}) \\
\pm \mathrm{SD}\end{array}$ & ${ }^{a} \mathbf{R} \mathbf{R}$ & ${ }^{b} \mathbf{R} \mathbf{R}$ & $\begin{array}{c}\mathrm{IC}_{50}(\mathrm{nM}) \\
\pm \mathrm{SD}\end{array}$ & ${ }^{a} \mathbf{R} \mathbf{R}$ & ${ }^{b} \mathbf{R} \mathbf{R}$ & $\begin{array}{c}\mathrm{IC}_{50}(\mu \mathrm{M}) \\
\pm \mathrm{SD}\end{array}$ & ${ }^{a} \mathbf{R} \mathbf{R}$ & ${ }^{b} \mathbf{R} \mathbf{R}$ \\
\hline Parental & A549 & $\mathrm{NE}$ & $\mathrm{NE}$ & $29.9 \pm 0.7$ & ND & ND & $39.8 \pm 0.1$ & ND & ND & $59.8 \pm 0.8$ & ND & ND \\
\hline $\begin{array}{l}\text { Paclitaxel } \\
\text { resistance }\end{array}$ & $\begin{array}{l}\text { A549- } \\
\text { PacR }\end{array}$ & $+1+$ & $\dagger$ & $92.8 \pm 2.1$ & 3.10 & 1.00 & $90.8 \pm 4.6$ & 2.28 & 1.00 & $82.3 \pm 4.3$ & 1.37 & 1.00 \\
\hline \multirow[t]{3}{*}{$\begin{array}{l}\text { Developed } \\
\text { cross-resis- } \\
\text { tance }\end{array}$} & $\begin{array}{l}\text { A549- } \\
\text { PacR/5- } \\
\text { FU }\end{array}$ & 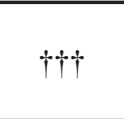 & $\dagger$ & $154.6 \pm 1.0$ & 5.17 & 1.66 & $103.2 \pm 1.8$ & 2.59 & 1.13 & $90.8 \pm 4.6$ & 1.51 & 1.10 \\
\hline & $\begin{array}{l}\text { A549- } \\
\text { PacR/ } \\
\text { DCT }\end{array}$ & t十t & $\dagger$ & $99.4 \pm 3.3$ & 3.32 & 1.07 & $102.4 \pm 2.9$ & 2.57 & 1.12 & $101.2 \pm 8.1$ & 1.69 & 1.22 \\
\hline & $\begin{array}{l}\text { A549- } \\
\text { PacR/ } \\
\text { CIS }\end{array}$ & $\dagger \dagger$ & $\dagger$ & $94.5 \pm 2.0$ & 3.16 & 1.01 & $89.8 \pm 2.0$ & 2.25 & 0.98 & $122.6 \pm 6.0$ & 2.03 & 1.47 \\
\hline Parental & PC-3 & $\mathrm{NE}$ & NE & $33.7 \pm 4.0$ & ND & ND & $63.2 \pm 5.9$ & ND & ND & $29.2 \pm 1.8$ & ND & ND \\
\hline $\begin{array}{l}\text { Paclitaxel } \\
\text { resistance }\end{array}$ & $\begin{array}{l}\text { PC-3- } \\
\text { PacR }\end{array}$ & $\dagger \dagger$ & $\dagger$ & $95.5 \pm 5.4$ & 2.83 & 1.00 & $97.5 \pm 10.1$ & 1.54 & 1.00 & $80.1 \pm 12.4$ & 2.74 & 1.00 \\
\hline \multirow[t]{3}{*}{$\begin{array}{l}\text { Developed } \\
\text { cross-resis- } \\
\text { tance }\end{array}$} & $\begin{array}{l}\text { PC-3- } \\
\text { PacR/5- } \\
\text { FU }\end{array}$ & tt & $t+\dagger$ & $142.4 \pm 3.1$ & 4.22 & 1.49 & $98.4 \pm 3.1$ & 1.55 & 1.01 & $91.2 \pm 2.3$ & 3.12 & 1.01 \\
\hline & $\begin{array}{l}\text { PC-3- } \\
\text { PacR/ } \\
\text { DCT }\end{array}$ & +1 & $\dagger$ & $98.8 \pm 2.1$ & 2.93 & 1.03 & $129.2 \pm 3.0$ & 2.04 & 1.32 & $91.1 \pm 10.3$ & 3.11 & 1.01 \\
\hline & $\begin{array}{l}\text { PC-3- } \\
\text { PacR/ } \\
\text { CIS }\end{array}$ & $\dagger \dagger$ & $\mathrm{NE}$ & $97.6 \pm 2.7$ & 2.89 & 1.02 & $100.2 \pm 4.1$ & 1.58 & 1.02 & $121.2 \pm 8.6$ & 4.15 & 1.34 \\
\hline Parental & H292 & $\mathrm{NE}$ & $\mathrm{NE}$ & $18.8 \pm 4.4$ & ND & ND & $32.1 \pm 2.1$ & ND & ND & $40.5 \pm 0.9$ & ND & ND \\
\hline $\begin{array}{l}\text { Gefitinib } \\
\text { resistance }\end{array}$ & $\begin{array}{l}\text { H292- } \\
\text { GefR }\end{array}$ & $\dagger$ & $\dagger$ & $24.8 \pm 3.1$ & 1.32 & 1.00 & $57.8 \pm 5.6$ & 1.80 & 1.00 & $51.2 \pm 3.0$ & 1.26 & 1.00 \\
\hline Parental & HEK293 & $\mathrm{NE}$ & $\mathrm{NE}$ & $10.0 \pm 1.0$ & ND & ND & $5.9 \pm 1.1$ & ND & ND & $5.0 \pm 3.4$ & ND & ND \\
\hline $\begin{array}{l}\text { Empty vec- } \\
\text { tor trans- } \\
\text { fected }\end{array}$ & $\begin{array}{l}\text { HEK293/ } \\
\text { Vector }\end{array}$ & $\mathrm{NE}$ & $\mathrm{NE}$ & $7.0 \pm 2.0$ & ND & ND & $8.2 \pm 1.0$ & ND & ND & $4.1 \pm 0.7$ & ND & ND \\
\hline $\begin{array}{l}\text { ABCB1- } \\
\text { GFP trans- } \\
\text { fected }\end{array}$ & $\begin{array}{l}\text { HEK293/ } \\
\text { ABCB1 }\end{array}$ & $\dagger$ & $\dagger$ & $21.6 \pm 3.2$ & 3.04 & 1.00 & $14.7 \pm 1.7$ & 1.78 & 1.00 & $20.0 \pm 1.0$ & 4.88 & 1.00 \\
\hline $\begin{array}{l}\text { Developed } \\
\text { cross-resis- } \\
\text { tance }(\mathrm{EV} \\
\text { transfection } \\
+5-\mathrm{FU})\end{array}$ & $\begin{array}{l}\text { HEK293/ } \\
\text { Vector/ } \\
\text { 5-FU }\end{array}$ & $\mathrm{NE}$ & $\mathrm{NE}$ & $10.1 \pm 2.3$ & 1.43 & 0.46 & $11.5 \pm 0.5$ & 1.40 & 0.78 & $5.5 \pm 1.0$ & 1.33 & 0.27 \\
\hline $\begin{array}{l}\text { Developed } \\
\text { cross-resis- } \\
\text { tance } \\
\text { (ABCB1- } \\
\text { GFP trans- } \\
\text { fection + } \\
\text { 5-FU) }\end{array}$ & $\begin{array}{l}\text { HEK293/ } \\
\text { ABCB1/ } \\
5-F U\end{array}$ & $+t^{\prime}$ & $\dagger$ & $54.2 \pm 4.6$ & 7.70 & 2.51 & $25.5 \pm 1.2$ & 3.10 & 1.74 & $44.8 \pm 1.0$ & 10.90 & 2.24 \\
\hline
\end{tabular}

${ }^{a}$ Fold drug resistance versus parental cell line.

${ }^{b}$ Fold drug resistance versus PacR, GefR, or ABCB1-GFP transfected cells phenotype.

Abbreviations used: WB; Western blot, RR; relative resistance, $\uparrow$; low level expression, $\uparrow \dagger$; medium level expression, $\dagger \dagger \dagger$;

high level expression, NE; no expression, ND; not determined. 
intracellular ATP levels was also observed in A549-PacR/5FU cells (Figure 3K). Interestingly, 5-FU cross-resistance in PacR cells caused minimal deficiency in the verapamilinduced regulation of $\mathrm{P}-\mathrm{gp} / \mathrm{ABCB} 1$ with prevented rapid $A B C B 1$ gene suppression, but there was an observed reduction in A549-PacR/5-FU cells (left panel, Figure 3L). Compared to the A549-PacR cell line, from which the PacR/5-FU variant was derived, verapamil caused a failure to inhibit P-gp expression and distribution (right panel, Figure 3L). These results argue that the physiological role of MDR in protecting cells from apoptosis may have different genetic drivers addressing $\mathrm{P}$-gp protection instead of the direct effects of drugs on P-gp. In support of this, it has been reported that PTX-resistance in breast cancer cells is associated with profound changes in the cell death response with the regulation of multiple apoptotic factors conferring platinum resistance [29].

\section{$F O X O 3 a$ regulates $A B C B 1$ transcription to coordinate the $T U B B 3$ response in PTX-resistant cancer cells with 5-FU cross-resistance}

To determine the mechanism by which regulated FOXO3a and TUBB3 levels affect P-gp-associated MDR in PTX-resistant cancer cells, we employed transient GFP-tagged-gene and/or siRNA transfections (see the Experimental Procedures) in A549-PacR/5-FU and PC-3-PacR/5-FU cells. The difficulty of identifying $T U B B 3$ effector genes and other interacting factors has been addressed in drug-resistant cancers because of the complexity of tubulin auto-regulation many years before identifying the association of $\beta$-tubulin isotypes and PTX resistance [30]. FOXO transcription factors regulate $\mathrm{mt}$ defects by regulating tubulin loops [19, 31]; although this observation has not yet been implicated in several malignancies, considerable progress has been made in associating FOXO-mediated $\mathrm{mt}$ stability regulation and taxol-resistance in some cancers. In A549-PacR and PC-3-PacR sublines with 5-FU cross-resistance, the overexpression of $F O X O 3 a$ up-regulated both $A B C B 1$ and $T U B B 3$ whereas the direct silencing of $A B C B 1$ caused incomplete inhibition of TUBB3 at both mRNA and protein levels (Figure 4A). To determine whether FOXO3a is able to directly regulate $T U B B 3$, the $F O X O 3 a$ gene was knocked down, and silencing $\mathrm{FOXO} 3 a$ was shown to directly inhibit $T U B B 3$ with both mRNA and protein expression completely suppressed (Figure 4B).

The ubiquitin-proteasome system has also been associated with $\beta_{\mathrm{III}}$-tubulin protein degradation and epigenetic regulation [32]. To further dissect how $\beta_{\mathrm{III}}{ }^{-}$ tubulin protein expression is controlled in cancer cells with MDR, we employed the ubiquitin-proteasome-dependent degradation pathway. When A549-PacR/5-FU and PC-3$\mathrm{PacR} / 5$-FU cells transfected with EV or FOXO3a-GFP are treated with the proteasome inhibitor, MG132, it suppresses the degradation of $\beta_{\mathrm{III}}$-tubulin in both cell models; furthermore, $F O X O 3 a$ enhances $\beta_{\mathrm{III}}$-tubulin activation with an observed 3-fold increased accumulation of TUBB3 turnover (Figure 4C, 4D). This finding suggests that the effect induced by MG132 pin-points the constitutive degradation of TUBB3 through its ubiquitination status. We further examined the status of TUBB3 poly-ubiquitination in these cells by transfecting the myc-tagged ubiquitin expression vector. After anti-TUBB3 immunoprecipitation followed by anti-myc antibody detection, we detected strikingly high molecular weight smears following MG132 treatment with higher polyubiquitinated levels in $\mathrm{FOXO} 3 a-$ siRNA transfected-cells relative to EV transfected cells, while lower poly-ubiquitination status in non-treated controls (Figure 4E). These results demonstrate that FOXO3a strikingly influences the physiological control of $\beta_{\text {III }}$-tubulin, at least in part, by the ubiquitin-proteome system, which can potentially modulate cross-resistance to 5-FU in PTX-resistant cancer cells.

Frequent aberrant DNA methylation of $A B C B 1$ has been observed in highly drug-resistant and invasive cancers, making its hypomethylation-triggering factors desirable targets for transcription-based inhibition, including the regulation of histone acetylation to reverse MDR [33, 34]. However, pivotal effectors that regulate $A B C B 1$ methylation and their precise epigenetic mechanisms have not yet been well elucidated. To determine whether the DNA methylation status of $A B C B 1$ is influenced by $F O X O 3 a$ to effect PTXresistance and MDR, we amplified our designed primers specific to both methylated and unmethylated alleles of the $-50 \mathrm{GC}$ and $-110 \mathrm{GC}$ boxes of $A B C B 1$. Among the several GC boxes of $A B C B 1$ that are essential for its activation, the $-50 \mathrm{GC}$ and $-110 \mathrm{GC}$ boxes are regarded to be highly relevant binding sites for $A B C B 1$ activators and repressors [35]. The -50GC box appeared to be slightly hypomethylated in $12 \mathrm{hr}$ culture whereas it displayed detectable methylation in $24 \mathrm{hr}$ culture, which was emphasized when the cells overexpressed $\mathrm{FOXO} a$ and received PTX treatment. The -110GC box was determined to have relatively higher methylation levels with the same observed status as that of the -50GC box when the cells overexpressed FOXO3a in $24 \mathrm{hr}$ culture (Figure 4F). To further confirm that the methylation modifications in PTX-resistant cells with 5-FU cross-resistance were stimulated in part by drugs, we employed a COBRA analysis of the cytosine-phosphateguanine $(\mathrm{CpG})$ site of the Inr region of $A B C B 1$. DNA methylation was increased after a relatively higher dose of PTX, 5-FU, and combination treatments (Figure 4G). Thus, the changes in $A B C B 1$ promoter methylation can be triggered partly by $F O X O 3 a$ overexpression and drugs, whereby cancer cells have acquired first-line resistance and cross-resistance.

To examine whether the $F O X O 3 a$-mediated regulation of $A B C B 1$ and subsequent $T U B B 3$ expression are influenced by $F O X O 3 a$ up-stream effectors, we determined the expressions of Akt signaling molecules that were highly associated with FOXO3a activity. We also employed 
A

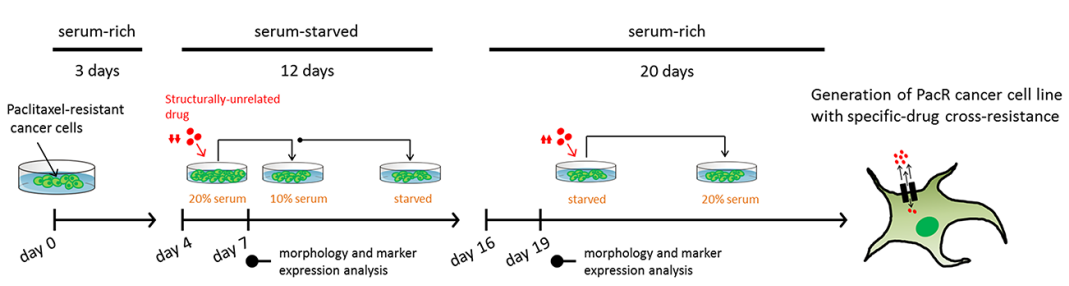

B
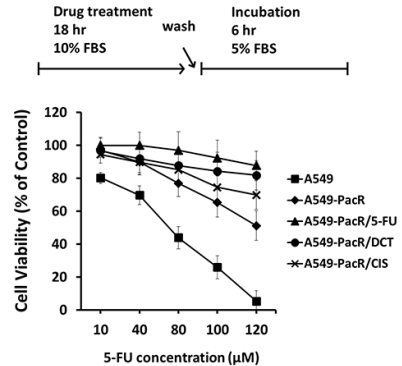

C

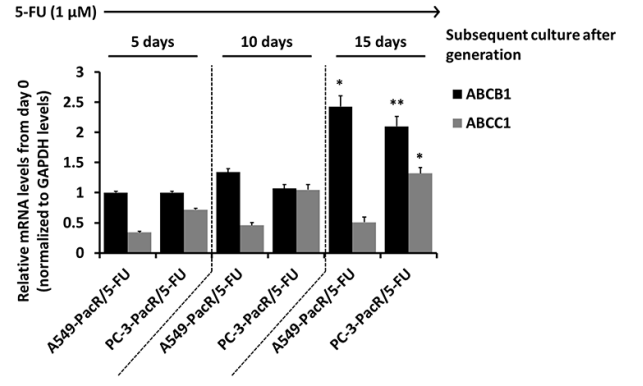

D

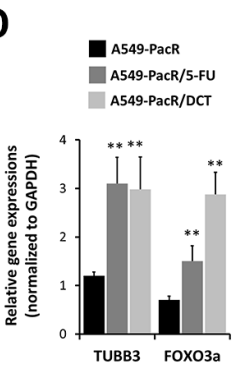

E

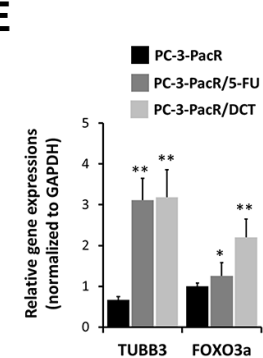

F

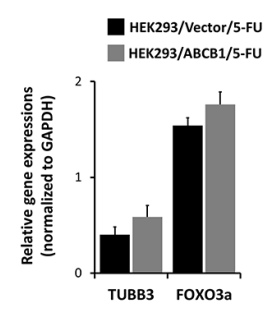

G

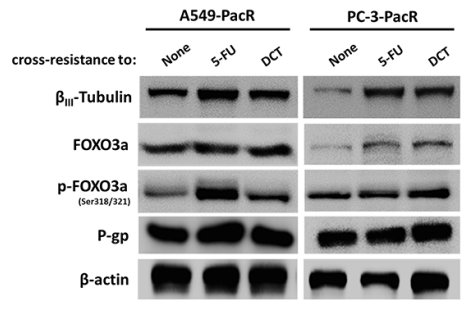

H

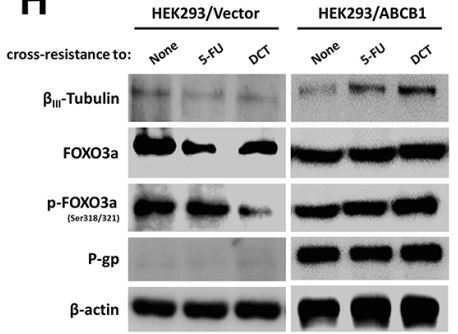

I

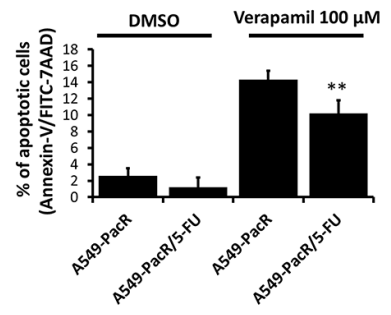

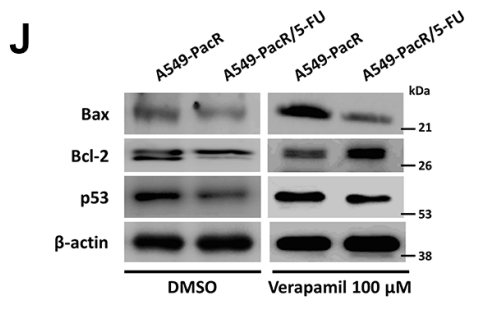

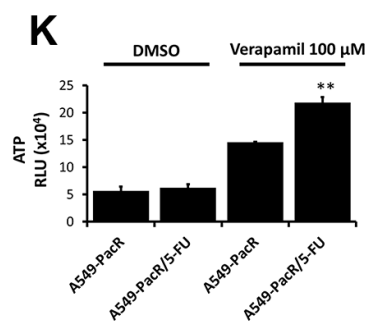

L
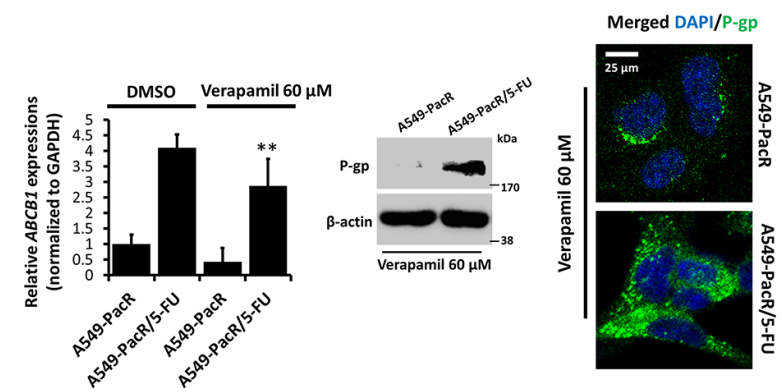

Figure 3: High acquired cross-resistance correlates to regulated TUBB3 and FOXO3a expressions with distinct hyperactive ABCB1 transcription in paclitaxel-resistant cancer cells. (A) Schematic diagram of general strategy used for the generation of transient cross-resistance to 5-FU, DCT, or CIS in PacR phenotype cancer cells or ABCB1-GFP transfected HEK293 cells. (B) Growth rate response of indicated cells (lower panel) to 5-FU treatment in a dose-dependent manner. Schematic schedule of treatment is also displayed (upper panel). Cell viability was determined using MTT assay. Data are represented as means \pm SEM. (C) Characterization for maintained $A B C B 1$ and $A B C C 1$ mRNA expressions in developed A549-PacR/5-FU and PC-3-PacR/5-FU cells after indicated subsequent cell cultures. Passages of cells were maintained with $1 \mu \mathrm{M} \mathrm{5-FU} \mathrm{final} \mathrm{concentration.} \mathrm{(D-F)} \mathrm{Characterization} \mathrm{for}$ TUBB3 and FOXO3a mRNA expressions in indicated developed transient cross-resistance in PacR phenotype derived from A549 (D), PC-3 (E), and in developed transient 5-FU cross-resistance derived from HEK293 (F) cells. (G and H) Western blot analysis of A549, PC-3-PacR cells (G) and HEK293 cells transfected with either empty vector or $A B C B 1$-GFP $(\mathrm{H})$ cells, all with developed transient cross-resistance to indicated drugs. Cells were assessed for expressions of indicated proteins after $24 \mathrm{hr}$ cell culture. (I) Flow cytometric determination of verapamil-induced apoptosis in indicated cells. Cells were treated with or without $100 \mu \mathrm{M}$ verapamil for $24 \mathrm{hr}$. Data are shown as bar graph represented as means \pm SEM. (J) Western blot analysis of indicated cells for expressions of apoptotic markers Bax, Bcl-2, and p53. Cells were treated with or without $100 \mu \mathrm{M}$ verapamil for $24 \mathrm{hr}$. (K) Intracellular ATP level assessment in indicated cells. Cells were treated with or without $100 \mu \mathrm{M}$ verapamil for $24 \mathrm{hr}$ and ATP levels were determined in $10^{4}$ fraction of cells. RLU, relative luciferase units. Data are represented as means \pm SEM. (L) Determination of verapamil-induced inhibition of P-gp/ABCB1 in indicated cells assessed through qRT-PCR (left), Western blotting (center) and confocal microscopy (right). Cells were treated with $60 \mu \mathrm{M}$ verapamil for $24 \mathrm{hr}$. Confocal images shown were magnified to $80 \mu \mathrm{m}$. 
doxorubicin to mechanistically identify the role of druginduced FOXO3a phosphorylation on P-gp expression because doxorubicin was found to induce Akt-dependent FOXO3a activity [36]. Doxorubin up-regulated Akt and FOXO3a and increased their phosphorylation in both A549-PacR/5-FU and PC-3-PacR/5-FU cells. FOXO3a overexpression derived more preserved doxorubicininduced p27/Kip1 activation except for I $\mathrm{I} B-\alpha$, which appeared to be unaffected in both conditions. Doxorubicin strikingly up-regulated P-gp and $\beta_{\mathrm{III}}$-tubulin expression in cells overexpressing FOXO3a (Figure 4H). Given that $\mathrm{PI} 3 \mathrm{~K} / \mathrm{Akt}$ signaling is involved in predominant MDR, which is further associated with the increase of doxorubicinmediated FOXO3a nuclear accumulation [37], these findings suggest that the involvement of $F O X O 3 a$ activity in regulating the $\mathrm{P}$-gp and $\beta_{\mathrm{III}}$-tubulin response involves a doxorubicin-induced PI3K/Akt mechanism. Interestingly, we found that in both drug-resistant phenotypes of the PC-3 cell line, PacR and PacR/5-FU, doxorubicin stimulated the methylation of FOXO3a at the arginine residues of the cells overexpressing FOXO3a (Figure 4I). This suggests that an alteration in the Akt-induced phosphorylation inhibition of FOXO3a through arginine methylation is associated with acquired resistance. We then studied whether the doxorubicin-induced nuclear translocation of FOXO3a is affected using PC-3-PacR/5-FU as a model. Notably, we found an increase in cytosolic FOXO3a when cells received doxorubicin alone or in combination with either PTX or 5-FU (Figure 4J, 4K), with doxorubicin alone causing cytosolic condensation of FOXO3a in the same cells (Figure 4L).

We next addressed whether MRP1 (encoded by $A B C C 1$ ) expression is involved in the $\mathrm{FOXO} 3 \mathrm{a}$-regulated $A B C B 1$ mechanism in the PC-3-PacR/5-FU phenotype because this specific model was found to overexpress MRP1 at higher levels compared to the same line of acquired resistance derived from A549 cells (see Table 1). We found no significant changes, although MRP1 is abundantly expressed in EV-transfected cells, whereas in FOXO3a overexpressing cells, doxorubicin induced MRP1 up-regulation in both protein and gene expression levels (Figure 4M). Similar to previous reports, this finding may support the high correlation of MRP1 hyperactivation with PTEN-controlled PI3K/Akt cascade in acquired drug resistance in prostate cancer cells [38].

\section{Drug-induced secretome factors promote FOXO3a-regulated P-gp function to confer multiple cross-resistance in PTX-resistant cancer cells}

Cancer growth and therapy resistance have been shown to be strongly regulated by soluble mediators from complex microenvironments that consist of secreted signals from immune, stromal, and cancer cells [39, 40]. Recent findings have suggested that signals derived from sensitive cancer cells in response to targeted therapies, such as kinase inhibitors, drive the outgrowth of drug-resistant cells [41]. Based on these findings and to refocus on cross-resistance manifestation, we hypothesized that signals derived from PTX-resistant cancer cells with cross-resistance to 5-FU and the PTX-analogue, DCT, can influence the contentious onset of multiple cross-resistance in first-line PTX-resistant cancers. To examine this speculation in vitro, we acquired conditioned media (CM) (see schematic diagram in Figure 5A) from PacR/5FU, PacR/DCT, and their combination (1:1 ratio) cultured with low-dose drug treatment and co-cultured this media with young passage A549-PacR cells (see schematic diagram in Figure 5B). We mixed CM from A549-PacR/DCT with DMSO-treated cell $\mathrm{CM}$ and performed subsequent $\mathrm{FOXO} 3 \mathrm{a}$ gene transfections; we combined A549-PacR/DCT-CM with A549-PacR/5FU-CM and performed subsequent TUBB3 RNAi; and we combined A549-PacR/5-FU-CM with A549-PacR/ DCT-CM and performed dual FOXO3a and $A B C B 1$ gene transfections. The rationale behind these combinations was based on previous findings relating the gene of interest to a specific class of cross-resistance occurring in drug-resistant cancers $[42,43,44]$. To study the effect of the above-described scheme on the FOXO3a-regulated $A B C B 1$ mechanism and $T U B B 3$ response in a more growthrelevant system, we performed a colony formation assay. PacR cells pre-exposed to DCT-CM following FOXO3aGFP transfection formed more drug-resistant colonies than EV-transfected cells. The transient knockdown of TUBB3 prevented the outgrowth of colonies derived from PacR cells pre-exposed to a combination of 5-FU-CM and DCT$\mathrm{CM}$, producing significantly lesser colonies than scramble control cells. Furthermore, the effect of TUBB3 knockdown on colony formation with the same drug combination$\mathrm{CM}$ pre-exposure was completely opposite that of cells overexpressing both $F O X O 3 a$ and $A B C B 1$ (Figure 5C), whereas the observation was significantly supported with the cell growth response of A549-PacR cells that experienced the same drug-CM pre-exposure as described above (A549-PacR/5-FU-CM) with subsequent dosedependent 5-FU treatment. Relative to cells transfected with either EV or scramble siRNA, FOXO3a overexpression promoted drug-resistant cell growth whereas the knockdown of $T U B B 3$ suppressed cell growth in a dosedependent manner (Figure 5D). To determine whether $F O X O 3 a$-induced growth promotion involves $A B C B 1$, we transfected the same cells with $A B C B 1$-GFP alone, co-transfection with $F O X O 3 a$-GFP, or transfection with their respective empty vectors. The cells overexpressing both $F O X O 3 a$ and $A B C B 1$ proliferated more rapidly than the cells overexpressing $A B C B 1$ alone following 5-FU treatment (Figure 5E). Consistent with the involvement of $A B C B 1$, A549-PacR cells that were pre-exposed to A549PacR/5-FU-CM followed by subsequent FOXO3a-GFP transfection displayed higher $\mathrm{P}$-gp distribution than control cells (Figure 5F). Employing the same scheme of drug-CM 


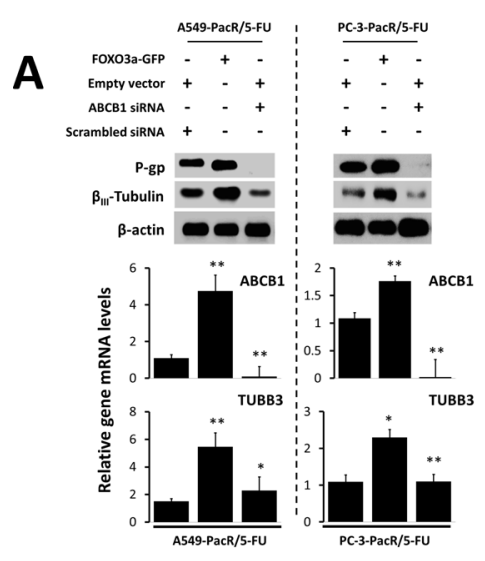

F
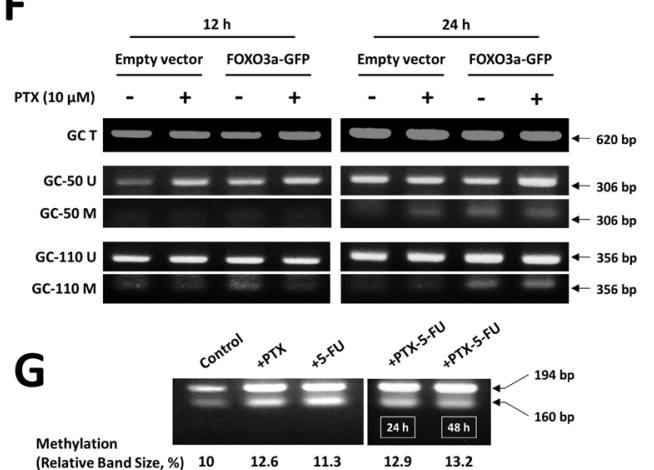

B

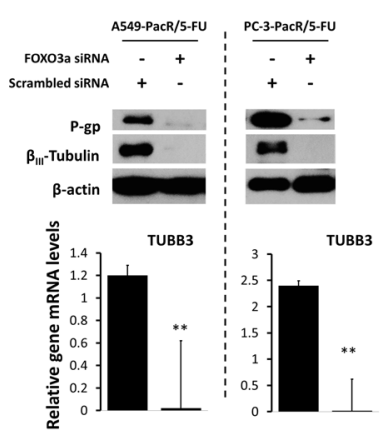

C

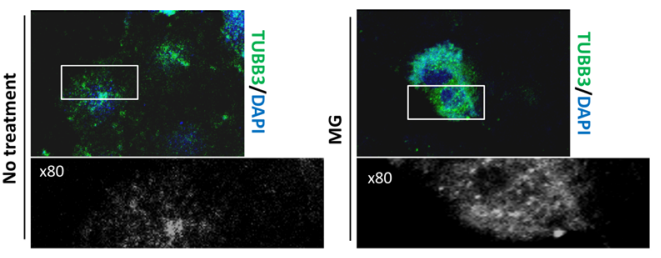

D
H

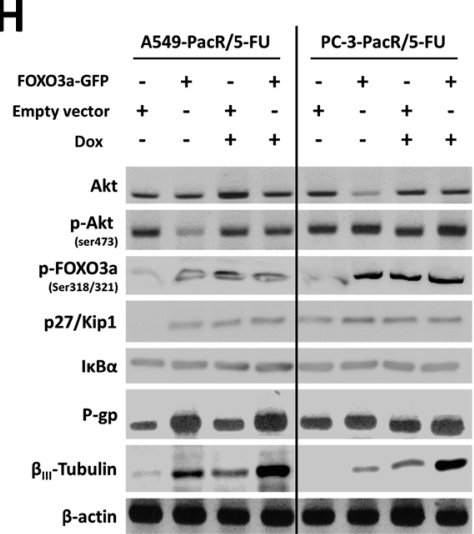

J

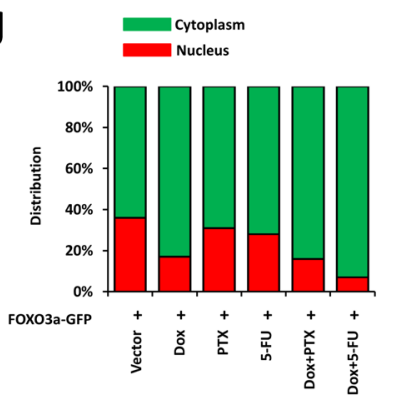

K

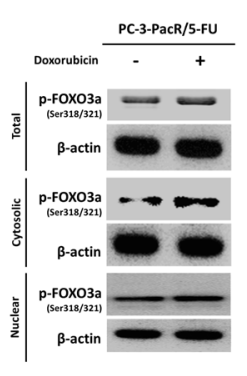

L

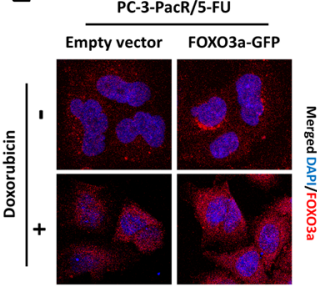

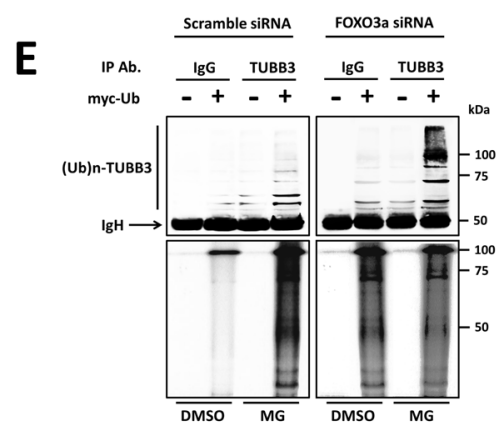

I
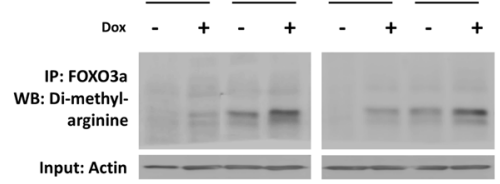

M

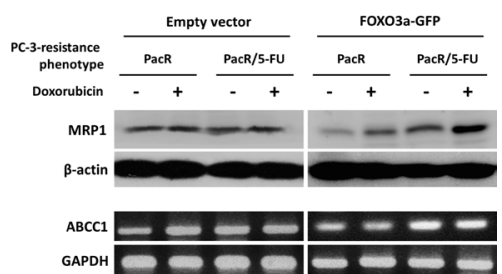

Figure 4: FOXO3a activity involves $\mathrm{ABCB} 1$ regulation to control TUBB3 response in paclitaxel-resistant cancer cells with transient 5-FU cross-resistance. (A) Characterization of ABCB1 and TUBB3 expressions at both protein (upper panel) and mRNA (lower panel) levels after transient transfections with indicated vectors or siRNA in A549-PacR and PC-3-PacR both with developed 5-FU transient cross-resistance. Cells were transfected with empty vector or FOXO3a-GFP and scrambled siRNA or ABCB1 siRNA for $48 \mathrm{hr}$. Data are represented as means \pm SEM. (B) Protein expressions (upper panel) of ABCB1 and TUBB3 and mRNA levels of TUBB3 (lower panel) in cells same as in A after transient transfection with either scrambled siRNA or FOXO3a siRNA for $48 \mathrm{hr}$. Data are represented as means \pm SEM. (C) Effect of proteasome inhibitor, MG132 (MG), on $\beta_{\mathrm{III}}$-tubulin distribution. Cells treated with or without $50 \mu \mathrm{M}$ MG for $24 \mathrm{~h}$ were subjected to immunocytochemistry. Magnified images were zoomed at $\times 80$. The cells were stained with TUBB3 antibody and DAPI. (D) Effect of MG on TUBB3 protein expressions in same cells as in A. Cells were transfected with either empty vector or FOXO3aGFP for $48 \mathrm{hr}$ and treated with or without $50 \mu \mathrm{M}$ MG132 for $24 \mathrm{hr}$. Whole-cell lysates were assayed by Western blotting. (E) Detection of ubiquitinated TUBB3 protein in A549-PacR/5-FU cells. Cells were transfected with either scramble siRNA or FOXO3a-siRNA for $48 \mathrm{hr}$ and cells were further transfected with an empty vector or myc-tagged ubiquitin-encoding vector for $24 \mathrm{hr}$. Immunoprecipitation was performed by TUBB3 antibody, then ubiquitinated proteins were detected by myc antibody assayed by Western blotting. (F) Methylationspecific PCR of $A B C B 1-50 \mathrm{GC}$ and -110GC boxes in A549-PacR/5-FU cells. Primer sets are designed to amplify methylated (M) and unmethylated (U) alleles. A primer set encoding the whole GC region (T) was used as loading control. Cells were transiently transfected with either empty vector or FOXO3a-GFP for $48 \mathrm{hr}$ and cells were treated with $10 \mu \mathrm{M}$ PTX for $12 \mathrm{hr}$ (left lane) or $24 \mathrm{hr}$ (right lane). (G) Combined bisulphite restriction analysis of the Inr ABCB1 promoter region in A549-PacR/5-FU cells treated with or without $10 \mu \mathrm{M}$ PTX, or $40 \mu \mathrm{M} 5-\mathrm{FU}$ for $24 \mathrm{hr}$ or in combination for 24 or $48 \mathrm{hr}$ as indicated. Figures represent the methylation percentages observed in the indicated drug-treated cells obtained from two separate independent experiments. (H) Effect of doxorubicin (Dox) on FOXO3a-induced regulation of Akt-related signals. Cells were transiently transfected with either empty vector or FOXO3a-GFP for $48 \mathrm{hr}$ and cells were treated with or without $2 \mu \mathrm{M}$ Dox for $8 \mathrm{hr}$. Protein expression levels were analyzed by Western blotting. (I) Methylated FOXO3a status in 
PC-3-PacR and -PacR/5-FU cells. Cells were transiently transfected with either empty vector or FOXO3a-GFP for 48 hr and cells were treated with or without $2 \mu \mathrm{M}$ Dox for $8 \mathrm{hr}$. Cell lysates were taken and dimethylated proteins at arginine residues were immunoprecipitated using anti-human FOXO3a antibody followed by Western blotting using anti-dimethyl arginine antibody. Actin was used as input. (J) Average GFP-positive cells determination in the nucleus or cytoplasm of PC-3-PacR/5-FU cells. Cells were transiently transfected with FOXO3a-GFP for $48 \mathrm{hr}$ followed by treatment with or without $2 \mu \mathrm{M}$ Dox, $300 \mathrm{nM}$ PTX, $120 \mu \mathrm{M}$ 5-FU or their indicated combinations for $8 \mathrm{hr}$. (K) Lysates of PC-3-PacR/5-FU treated with or without $2 \mu \mathrm{M}$ Dox for $8 \mathrm{hr}$ were subjected to cytoplasmic or nuclear extraction followed by Western blotting. (L) Confocal microscopic analysis of PC-3-PacR/5-FU cells. Cells were transiently transfected with either empty vector or FOXO3a-GFP and cells were treated with or without $2 \mu \mathrm{M}$ Dox for $8 \mathrm{hr}$ and stained with FOXO3a antibody and DAPI. Images shown were magnified at $60 \mu \mathrm{m}$. (M) Characterization of ABCC1 expressions at both protein (upper panel) and gene transcript (lower panel) levels in both PC-3-PacR and-PacR/5-FU cells. Cells were transiently transfected with either empty vector or FOXO3a-GFP for $48 \mathrm{hr}$ and cells were treated with or without $2 \mu \mathrm{M}$ Dox for $8 \mathrm{hr}$.

exposure, transient gene and/or siRNA transfections as in Figure 5B, we found regulated gene expressions of TUBB3 (left panel) and protein expressions of $\beta_{\mathrm{III}}$-tubulin, P-gp, and MRP1 (right panel) in A549-PacR cells, suggesting that the secreted factors from 5-FU cross-resistant PacR cells influence the promotion of MDR through a $F O X O 3 a$ directed $A B C B 1$ mechanism (Figure 5G). Notably, in the same cells, the overexpression of either FOXO3a or both $F O X O 3 a$ and $A B C B 1$ subsequently induced the activation of MRP1.

To functionally characterize the effects of $\mathrm{FOXO3a}$ on P-gp activity, we addressed the drug efflux function of the P-gp pump incorporating the Rho-123 and ABCB1 ATPase assays. FOXO3a overexpression significantly blocked the intracellular accumulation of the Rho-123 fluorescent substrate following 5-FU and DCT treatment, which was supported by the suppression of ABCB1 ATPase activity (Figure 5H left panel). Correspondingly, $T U B B 3$ knockdown resulted in enhanced accumulation of the substrate and increased ABCB1 ATPase activity (Figure 5H right panel). Accordingly, TUBB3 knockdown sensitized the cells to 5-FU, resulting in fewer formed colonies compared to control cells upon drug exposure (Figure 5I).

To understand the role of secreted signals from A549-PacR cells with multiple acquired cross-resistance in promoting P-gp-associated MDR, we directly harvested CM from A549-PacR/5-FU, A549-PacR-/DCT, and A549PacR-/CIS cells followed by individual or combination transient gene or siRNA transfections (see scheme in Figure 5J). The TUBB3 gene response to various transfections was determined by qRT-PCR (Supplementary Figure 2) and was used as an indicative mechanism factor in consequent cell growth and Rho-123 accumulation. Drug-resistant cells progressed significantly more rapidly when $T U B B 3$ was activated in response to co-transfection of $F O X O 3 a$-GFP and $A B C B 1$-GFP whereas cell growth progressed more slowly when $T U B B 3$ was negatively regulated in response to co-transfection of $\mathrm{FOXO3a-}$ siRNA and ABCB1-siRNA (Figure 5L). Verifying this finding, Rho-123 intracellular accumulation was inhibited when $T U B B 3$ was suppressed whereas Rho-123 substrate accumulation was increased when TUBB3 was activated in response to similar gene modifications as described above (Figure 5M). The results of the cell growth and Rho123 accumulation assays for cells transfected with gene/
siRNA respective controls ( $\mathrm{EV}$, scramble siRNA) can be observed in Supplementary Figure 3; although measurable, no significant differences were found. Taken together, these data indicate that secretome factors from PTX-resistant cancer cells with acquired cross-resistance can sufficiently influence MDR in first-line PTX-resistant cancers cells with impaired FOXO3a-regulated ABCB1 activity and can be predicted by $T U B B 3$ feedback.

Meanwhile, the above described regulatory effects of transient TUBB3 knockdown on P-gp function may not be translated to GEF resistance because the reversal of drug resistance after siRNA-mediated silencing was not observed in H292-GefR cells (Supplementary Figure 4A, 4B). Notably, TUBB3 knockdown did not significantly affect P-gp efflux and ATPase activities (Supplementary Figure $4 \mathrm{C}, 4 \mathrm{D})$, which can be traced on the preserved $A B C B 1$ and $A B C C 1$ mRNA levels even after 5-FU and DCT stimulation (Supplementary Figure 4E, 4F, 4G). These results suggest that modification of TUBB3-directed effects on P-gp regulation and cross-resistance can only be implied to PTXresistant cancer cells.

\section{Transient knockdown of $T U B B 3$ supresses the $A B C B 1$-associated aggressive cell phenotype and alters subcutaneous tumor physiology}

PTX-resistant cancers highlight the acquisition of an aggressive phenotype exhibiting abnormal nuclear morphology and faster cytoskeletal remodeling dynamics $[43,44]$. To elaborate the involvement of TUBB3 in the mechanism by which acquired PTX-resistance and 5-FU cross-resistance develop aggressiveness, we employed various cell-based and protein expression assays that characterize cancer cell invasiveness. In both A549PacR and A549-PacR/5-FU developed phenotypes, $T U B B 3$ knockdown induced an increase in the $\mathrm{G}_{0} / \mathrm{G}_{1}$ transition phase, resulting in an increased $\mathrm{G}_{1} / \mathrm{S}$-phase ratio compared to both controls (Figure 6A). Similarly, scant $T U B B 3$ transcription resulted in an expedited S-phase fraction identified by BrdU incorporation, down-regulated the phosphorylation of Akt and ERK, and promoted the inhibition of cell-cycle regulatory proteins, thus collectively explaining the gradual decrease in cell growth (Figure 6B, 6C). In relation, our preliminary findings on 5-FU stimulated outgrowth of A549-PacR cells suggest that $T U B B 3$ deficiency reduces the cells contentious 
B

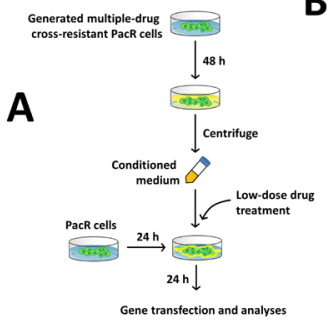

F

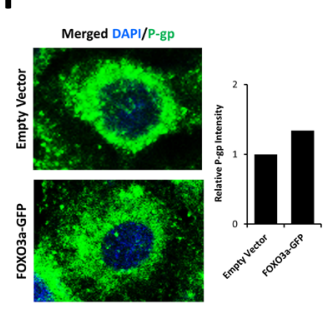

H

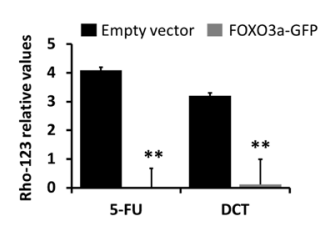

K

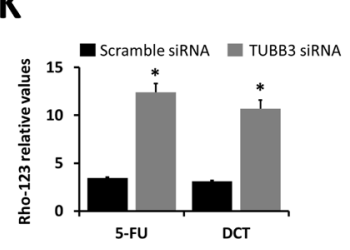

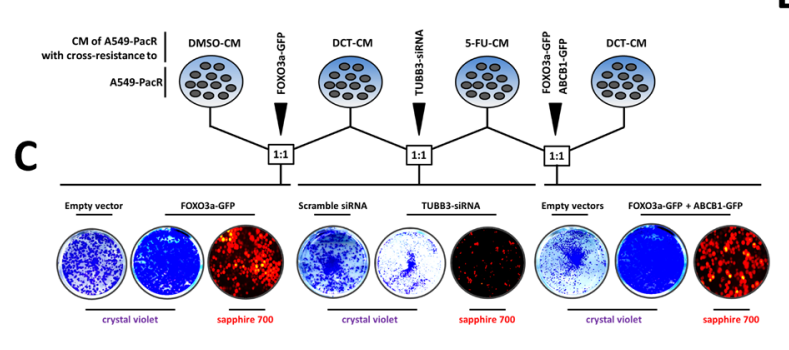

G
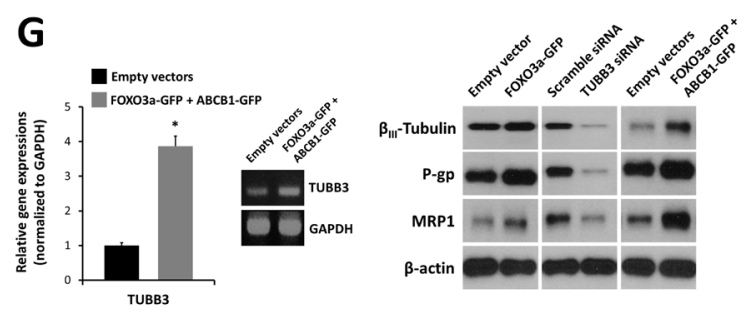

I
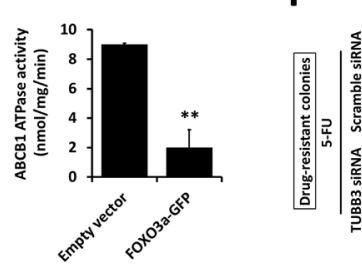

L

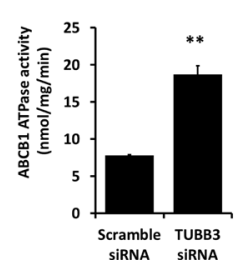

D

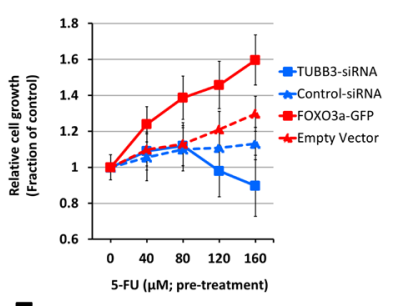

E
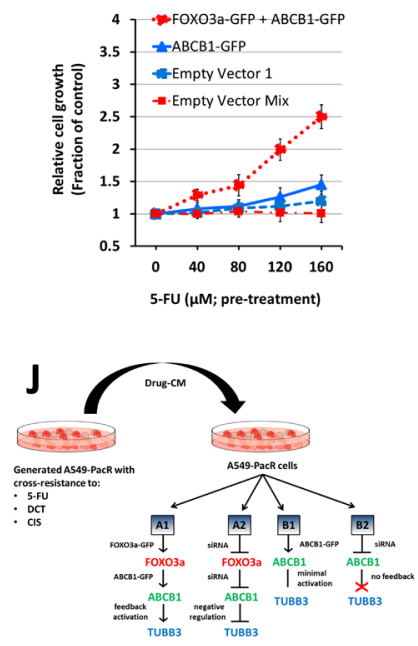

M

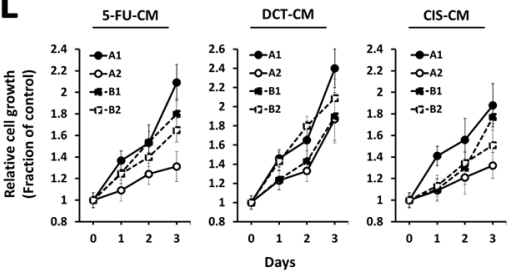

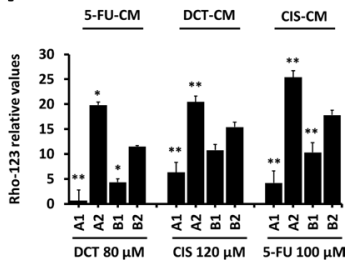

Figure 5: Drug-induced secretome factors influence MDR promotion of FOXO3a-regulated P-gp activity in PTXresistant A549 cells with multiple cross-resistance. (A) Schematic diagram of the drug conditioned media (CM)-exposure procedure used in various assays (B-J). (B and C) Characterization of FOXO3a-mediated multiple cross-drug resistance in A549-PacR cells (B). Cells were preincubated with indicated 1:1 combination ratio of CM from DMSO-, DCT-, 5-FU-treated cells. After $24 \mathrm{hr}$, cells were transiently transfected with indicated vectors or siRNA for $48 \mathrm{hr}$ and assessed for colony formation (C). Established drug resistant colonies were stained and visualized by crystal violet or sapphire 700. (D and E) TUBB3 knockdown or FOXO3a overexpression (D) and overexpression of $\mathrm{ABCB} 1$ and FOXO3a effects on growth rate of A549-PacR/5-FU cells (E). A549-PacR/DCT cells were treated with indicated 5-FU concentrations for $24 \mathrm{~h}$ then CM was collected. Adherent A549 cells were exposed to the collected CM for $24 \mathrm{~h}$ followed by transient transfection with indicated vectors or siRNA for $48 \mathrm{hr}$. Cell viability was assessed by MTT assay. Data are represented as means \pm SEM. (F) Confocal microscopic analysis of A549-PacR/5-FU cells. Cells were transiently transfected with indicated vectors or siRNA for $48 \mathrm{hr}$ and stained with P-gp antibody and DAPI. Images shown were magnified to $80 \mu \mathrm{m}$. (G) Western blot analysis (left) and agarose gel electrophoresis of qPCR products of A549-PacR/5-FU cells. Cells were transiently transfected with indicated vectors or siRNA for $48 \mathrm{hr}$ and assessed for expression studies. (H) ABCB1 drug efflux activity of A549-PacR/5-FU cells. Cells were transiently transfected with either empty vector or FOXO3a-GFP for $48 \mathrm{hr}$ and cells were treated with or without $100 \mu \mathrm{M} 5$-FU or $120 \mu \mathrm{M}$ DCT for $24 \mathrm{hr}$. Drug-treated cells were assayed for Rhodamine-123 (Rho-123) uptake (left) and untreated cells were assayed for ABCB1 ATPase activity (right). Data are represented as means \pm SEM. (I) ABCB1 drug efflux activity of A549-PacR/5-FU cells. Cells were transiently transfected with either scrambled siRNA or TUBB3 siRNA for $48 \mathrm{hr}$ followed by drug treatment and assayed as in $\mathrm{H}$. Data are represented as means \pm SEM. (J) Multidrug resistant colonies. Cells were transiently transfected with either scramble siRNA or TUBB3 siRNA for $48 \mathrm{hr}$ and cells were treated with $30 \mu \mathrm{M}$ 5-FU for 7 days. Resistant colonies were visualized by sapphire 700. (K) Schematic diagram of drug CM exposure and respective TUBB3 feedback after induced gene expression changes via transient gene transfection or siRNA gene silencing. Indicated gene or siRNA transfection schemes were used in L and M for P-gp functional assays. (L) Growth rate of A549-PacR/5-FU cells. Cells were pre-incubated with indicated drug-CM and cells were transiently transfected with indicated genes or siRNA for $48 \mathrm{hr}$. Cell viability was assessed by MTT assay. Data are represented as means \pm SEM. (M) ABCB1 drug efflux activity A549-PacR/5-FU cells. Cells were preincubated with indicated drug-CM and cells were transiently transfected with indicated genes or siRNA for $48 \mathrm{hr}$. Cells were then treated with indicated drugs and concentration for $36 \mathrm{hr}$. Data are represented as means $\pm \mathrm{SEM}$. 
growth rate but fails to induce complete attenuation (Supplementary Figure 5). Targeted silencing of TUBB3 regulated the protein expressions of EMT markers, revealing a general trend away from the epithelium and towards the mesenchyme (Figure 6D). Interestingly, the distribution of vimentin in A549-PacR/5-FU control cells was condensed in the cytoplasm, and some appeared to be atypical to the nucleus. The same cells with silenced TUBB3 expression inhibited the immunofluorescence of vimentin (Figure 6E). Along with Akt and ERK signals, the classical EMT markers encompass key factors that regulate drugresistant aggressiveness [45]. This may suggest that modification of $\mathrm{mt}$ stability through TUBB3 affects the distinctive EMT-driven hostile outgrowth of the tumor intercellular system in cancers with MDR, at least in vitro.

We next elucidated the probable involvement of Akt by incorporating the LY294002 inhibitor. The knockdown of TUBB3 escalated the LY294002-induced Akt-inhibition in A549-PacR/5-FU cells at the protein level compared to scramble siRNA-transfected cells except with little alteration between non-treated and LY294002-treated siTUBB3-transfected cells (Figure 6F). In addition, a concurrent increase in intracellular ATP levels was evident in siTUBB3-transfected cells compared to scramble siRNAtransfected cells in both A549-PacR and A549-PacR/5-FU cells (Figure 6G). This prompted us to further evaluate the association of TUBB3-induced Akt activity suppression in cell mobility and invasiveness. The same attenuation of TUBB3 siRNA-induced effects were observed in the Akt-dependent promotion of intrinsic apoptosis, which supports escape from drug-induced apoptosis (Figure 6H), and in cell migration, invasion, and colony formation in soft agar, indicating that the metastatic aggressiveness of PTX-resistant cells with acquired cross-resistance, at least to 5-FU, can be controlled by TUBB3 (Figure 6I).

In support of the identified TUBB3-dependent effects in multidrug resistance in vitro, a tumor xenograft model was used to examine the probable drug resistanttumor physiological alteration in vivo by modifying TUBB3 transcription. The nude mice were randomized and subcutaneously engrafted with A549-PacR/5-FU and $\mathrm{PC}-3-\mathrm{PacR} / 5-\mathrm{FU}$ cells transfected in vitro with either scramble siRNA or TUBB3 siRNA. At the termination of the experiment (35 days after inoculation) (see in vivo experiment scheme in Figure 6J), the TUBB3 deficient tumors showed less condensed tumor mass and induced susceptibility to apoptosis (Figure 6K). These data confirmed that the described genetic and other substantial factors affecting TUBB3 transcription directly affect metastatic tumor progression of drug-resistant cancer cells, specifically PTX-resistant tumors with acquired crossresistance to unrelated drugs (at least to 5-FU and CIS). Preliminarily, we observed the regression of tumor growth using a small-size sample group in TUBB3-deficient subcutaneous tumors. The subcutaneous tumor mass (in grams; g) of the control group was approximately $1.98 \mathrm{~g}$
( $n=2 ; 8$ isolated tumor xenografts of A549-PacR/5-FU) and $0.89 \mathrm{~g}(n=2 ; 8$ isolated tumor xenografts of PC-3PacR/CIS), whereas the mass of the tumor induced by TUBB3 siRNA-transfected cells was inhibited by $19 \%$ $(p<0.011)$ and $32 \%(p<0.005)$ with tumor masses of approximately $1.62 \mathrm{~g}(n=2 ; 8$ isolated tumor xenografts of A549-PacR/5-FU) and $0.61 \mathrm{~g}(n=3 ; 12$ isolated tumor xenografts of PC-3-PacR/CIS) (Supplementary Figure 8), respectively.

A biochemical analysis of the tumor tissues was performed to substantiate the in vitro findings and evaluate those findings in a more physiologically-relevant manner. We confirmed the in vivo transient siRNA transfection efficiency by qRT-PCR using RNA extracted from tumor samples. TUBB3 siRNA reduced the TUBB3 mRNA level by $47 \%$ and the $A B C B 1$ mRNA level by $19 \%$ in A549$\mathrm{PacR} / 5-\mathrm{FU}$-induced subcutaneous tumors whereas in PC-3-PacR/CIS tumors, TUBB 3 was reduced by $31 \%$ and $A B C B 1$ by $29 \%$ relative to the mRNA levels from tumors induced by scramble siRNA transfected cells (Figure 6L). To further elaborate the consequences of scant TUBB3 on $\mathrm{P}$-gp expression, we determined their protein expression levels in extracts from frozen xenograft tumor tissue samples. We observed down regulated levels of $\beta_{\mathrm{III}}$-tubulin and P-gp in TUBB3-deficient subcutaneous tumors. We then determined the gene expressions of $A k t$ and $V E G F$ in an attempt to explain their effects on tumor progression. A similar paradigm in which tumor endothelial cells acquire drug resistance involving Akt and VEGF signaling to promote metastatic tumor growth was previously reported [46]. Thus, reduced tumor mass in response to TUBB3 knockdown is influenced by Akt and VEGF signals, which we found to suppress Akt gene expression and attenuate $V E G F$ levels in A549-PacR/5-FU tumors (Figure 6N). These results confirm the regulation of Akt signaling in modified TUBB3 status associated with acquired crossresistance in PTX-resistant cancer in vivo and in vitro.

\section{FOXO3a-directed feedback control of TUBB3 transcription confines PTX-targeted microtubule stability in PTX-resistant A549 cells with acquired cross-resistance}

Notably, although several cancer cell models of mt-stabilizing drug resistance (e.g., taxol) have been concomitantly associated with reduced $\mathrm{mt}$ stability $[47,48]$, a precise characterization of tubulin dynamics in A549 cells with acquired MDR has not yet been welldescribed. We then identified whether the tubulin dynamics in the resistant phenotypes we developed had changed relative the mt status of parental A549 cells. The tubulin microtubules (pellet fraction, $\mathrm{P}$ ) were measured after being separating from free tubulin in the cytosol (supernatant fraction, S). The cells confirmed to have PTX resistance had lower levels of tubulin in their microtubules compared to the parental cells. This manifestation was attenuated 
A

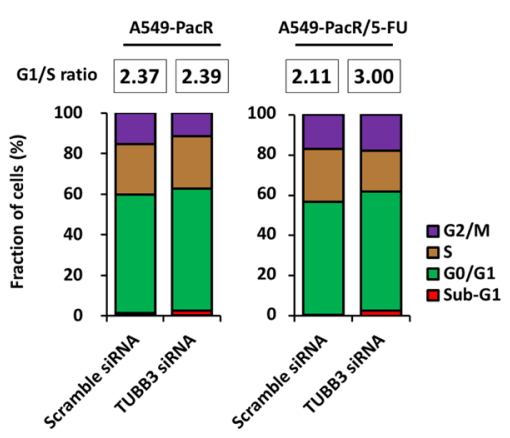

C

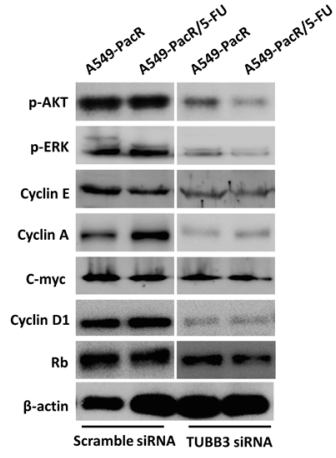

D

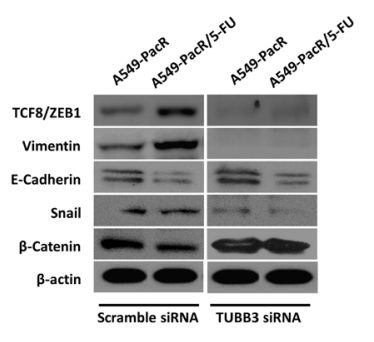

E

Merged DAPI/Vimentin
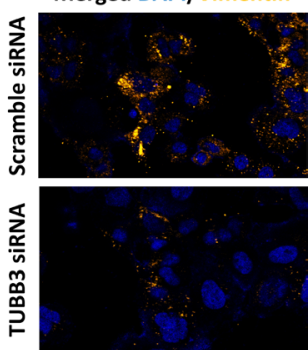

B

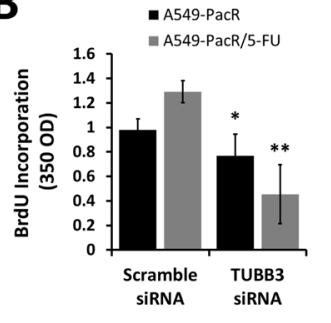

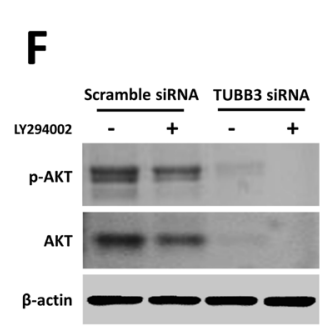

G

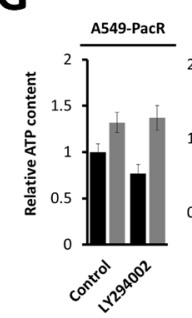

H

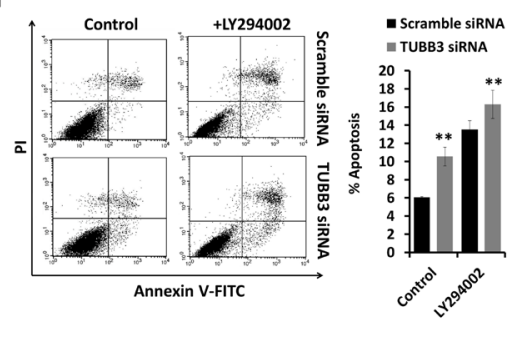

I
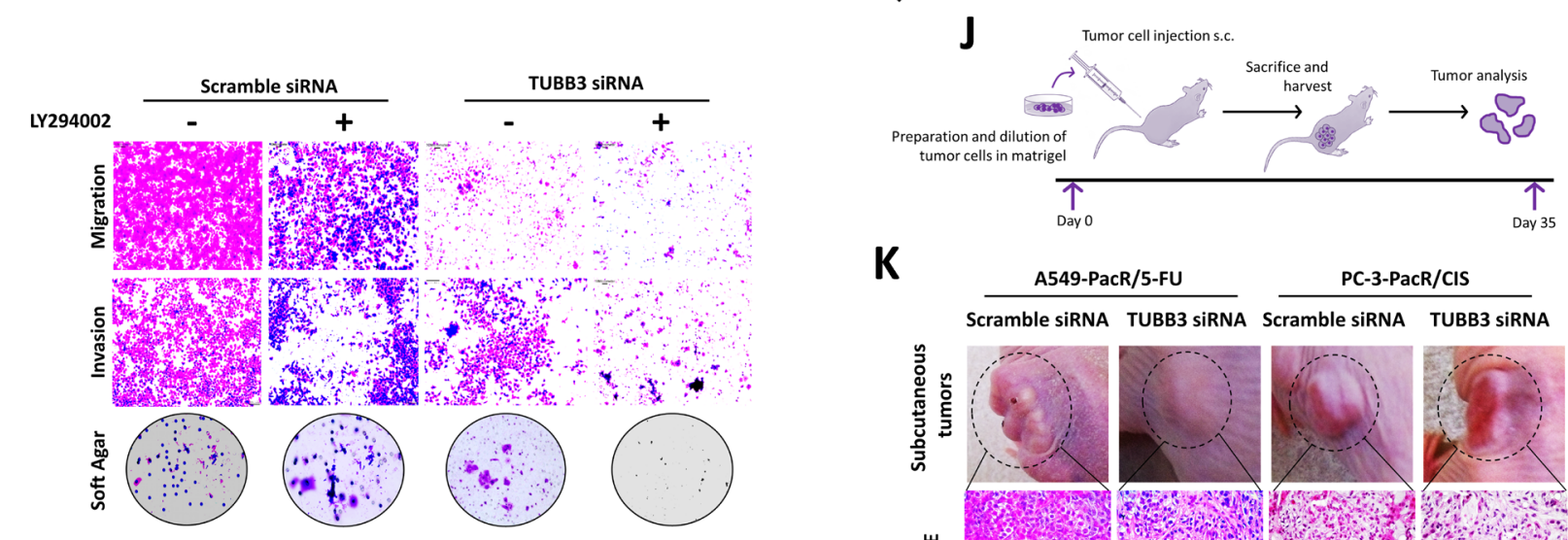

K

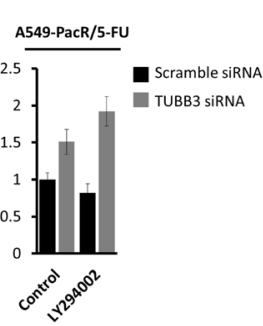

$\frac{\text { A549-PacR/5-FU }}{\text { Scramble siRNA TUBB3 siRNA Scramble siRNA TUBB3 siRNA }}$

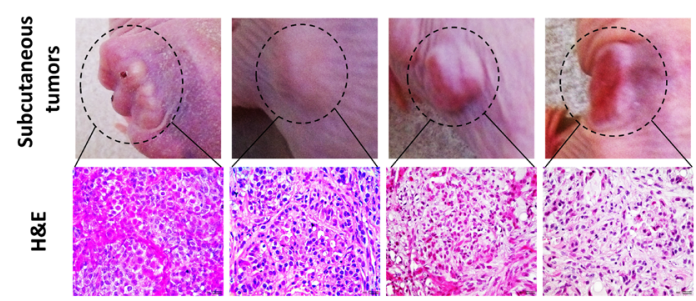

L
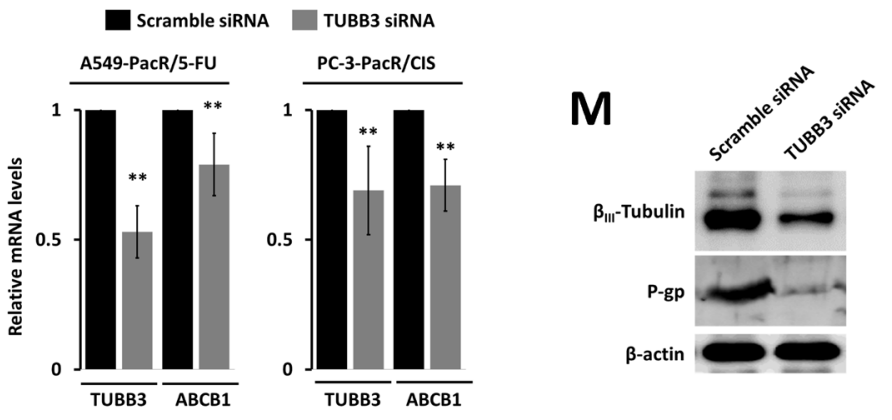

$\mathbf{N}$

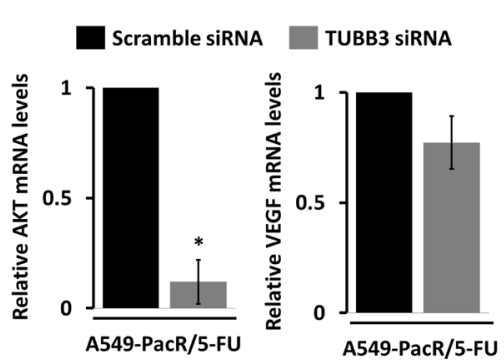

Figure 6: TUBB3 deletion involves AKT to alter the aggressive phenotype and tumor physiology of paclitaxel-resistant cancer with developed transient multiple cross-resistance. (A and B) Cell cycle progression of A549-PacR and -PacR/5-FU cells. Cells were transiently transfected with either scramble siRNA or TUBB3 siRNA for $48 \mathrm{hr}$. Transfected cells were subjected to FACS analysis (A) and BrdU incorporation assay (B). G1/S ratio of cells was calculated and displayed. Data are represented as means \pm SEM. (C) Cell cycle regulation in A549-PacR and -PacR/5-FU cells. Cells were transiently transfected with either scramble siRNA or TUBB3 siRNA for $48 \mathrm{hr}$. Cells were then subjected to Western blotting to detect cell cycle regulatory proteins. (D) Epithelial-to-mesenchymal transition (EMT) status of A549-PacR and -PacR/5-FU cells. Cells were transiently transfected with either scramble siRNA or TUBB3 siRNA for $48 \mathrm{hr}$. Classical EMT markers were immunoblotted. (E) Immunofluorescence images of Vimentin in A549-PacR/5-FU cells. Cells were transiently transfected with either scramble siRNA or TUBB3 siRNA for $48 \mathrm{hr}$. Cells were stained with Vimentin antibody and DAPI. Images shown were magnified at $30 \mu \mathrm{m}$. (F) Inhibition of AKT in A549-PacR/5-FU cells. Cells were transiently transfected 
with either scramble siRNA or TUBB3 siRNA for $48 \mathrm{hr}$ and cells were treated with or without $10 \mu \mathrm{M}$ of AKT inhibitor, LY294002, for $18 \mathrm{hr}$. Phosphorylation of AKT was assayed by Western blotting. (G) Intracellular ATP assessment of A549-PacR and -PacR/5-FU cells. Cells were transiently transfected with either scramble siRNA or TUBB3 siRNA for $48 \mathrm{hr}$ and cells were treated with or without $10 \mu \mathrm{M}$ LY294002 for $18 \mathrm{hr}$. ATP levels was assessed. Data are represented as means \pm SEM. (H) AKT-dependent apoptosis in A549-PacR/5-FU cells. Cells were transiently transfected with either scramble siRNA or TUBB3 siRNA for $48 \mathrm{hr}$ and cells were treated with or without $10 \mu \mathrm{M}$ LY294002 for $18 \mathrm{hr}$. Cells were analyzed for annexin-V/FITC-PI by FACS. Data are represented as means \pm SEM. (I) Motility and colony formation of A549-PacR/5-FU cells. Cells were transiently transfected with either scramble siRNA or TUBB3 siRNA for 48 hr and cells were treated with or without $10 \mu \mathrm{M}$ LY294002 for $18 \mathrm{hr}$ in culture subjected to migration, invasion, and colony formation assays. (J) Schematic diagram of in vivo tumor xenograft experiments. (K) Evaluation of subcutaneous tumors. Indicated cells were transiently transfected with either scramble siRNA or TUBB3 siRNA for $48 \mathrm{hr}$. Transfected cells $\left(1 \times 10^{6}\right.$ cells/flank $)$ were subcutaneously injected into the flanks of nude mice. Shown representative images depict the actual tumors prior to surgery and measurement (upper) and H\&E (lower) immunohistochemical analysis indicated xenograft tumors. Stained sections were photographed with an inverted phase-contrast microscope with 150× magnification. (L) Relative expressions of ABCB1 and TUBB3 in tumor transcripts of indicated xenografts. Total RNA was isolated and analyzed by quantitative reverse transcriptase-PCR using ABCB1-, or TUBB3-specific primers and normalized to GAPDH expression. Data are represented as means \pm SEM. (M) Protein expressions of $\beta_{\mathrm{III}}$-tubulin and P-gp in A549-PacR/5-FU xenograft tumors. Tumor sample lysates were immunoblotted with the indicated antibodies. (N) Relative expressions of AKT and VEGF in tumor transcripts of A549-PacR/5-FU. RNA was processed as in L. Data are represented as means $\pm \mathrm{SEM}$.

by the subsequent acquisition of 5-FU cross-resistance. Surprisingly, although it is a PTX-analogue, transient crossresistance to DCT strikingly destabilized tubulin dynamics, and the development of cross-resistance to a combination of 5-FU and DCT completely undermined tubulin levels in $\mathrm{mt}$. In PacR cancer cells with cross-resistance to 5-FU, DCT, and 5-FU+DCT, the regulation of tubulindependent $\mathrm{mt}$ stability, which showed an impaired $\mathrm{mt}$ status, was evident and was strictly responsive to increasing concentrations of PTX (Figure 7A). This suggests that the acquisition of PTX resistance has less stable $\mathrm{mt}$ and that the development of cross-resistance to other agents can augment this event, showing more impaired $\mathrm{mt}$ dynamics through the modification of tubulin in $\mathrm{mt}$. The stability of $\mathrm{mt}$ can be represented by the acetylation status of $\mathrm{mt}$ because post-translationally, tubulin is modified by $\mathrm{mt}$ acetylation, which directs conserved $\mathrm{mt}$ dynamics [49]. Because less tubulin was found in A549 cells with PTXresistance and developed cross-resistance, this prompted us to measure the acetylated microtubules in the lysates of A549, A549-PacR, and A549-PacR/5-FU cells treated with or without PTX using an acetylated tubulin-specific antibody. Acquired PTX resistance and cross-resistance resulted in lower acetylation of tubulin than parental cells (Figure 7B). Combined with the reduced amount of $\mathrm{mt}$ found in the MDR phenotype, these data suggest that firstline PTX resistance confers less stable microtubules, which can further be augmented with the consequential onset of cross-resistance, at least to 5-FU.

To examine whether a soluble factor required for tubulin polymerization was influenced in the resistant sublines and whether it can differentiate, to a certain degree, the less stable $\mathrm{mt}$ we found as described above, we performed a mixing experiment. Whole cell lysates from A549-PacR cells were added to the lysate from A549PacR/5-FU cells at varying ratios of 1:1, 1:4, and 1:19 (PacR:PacR/5-FU) to examine whether PTX resistance could affect the state of polymerization in the 5-FU crossresistant lysate, which we further associated with a PTXtargeted mt mechanism by incorporating PTX treatment. In A549-PacR cells, although slightly attenuated, most of the tubulin is present in the polymerized form (Pol), in contrast to A549-PacR/5-FU cells, in which the majority of the tubulin is in the soluble form (Sol). This is an interesting observation because a significant difference has been identified between PacR and PacR/5-FU cells associated with tubulin polymerization. Further, the addition of lysate from PacR cells at a higher fraction of PacR/5-FU lysates did not induce polymerization of tubulin but was more polymerized when the lysate fraction from the PacR/5-FU variant was decreased (Figure 7C). Thus, there is partially an induction of polymerization amended by PacR cells to 5-FU cross-resistant subline PacR cells, which is associated with the recruitment of tubulin in the presence of polymerized tubulin. Next, we addressed the functional mechanism by which modification on TUBB3 transcription affects $\mathrm{mt}$ stability and tubulin polymerization. In A549-PacR/5-FU cells, upon incorporating the transient transfection of $F O X O 3 a$ and $A B C B 1$ genes or siRNAs, $T U B B 3$ gene expression can be modified correspondingly. Using these feedback control patterns, as verified by qRTPCR (see scheme in Figure 7D, 7E), we subjected the control transfected cells (EV) and transfection schemedependent transfected cells (TS) based on the TUBB3 response to the same assay of $\mathrm{mt}$ stability as that described in the method used for Figure 7C. The successful negative regulation of TUBB3 through the co-transfection of both $F O X O 3 a$ and $A B C B 1$ siRNAs conferred stabilization of the cytoskeletal $\mathrm{mt}$ through tubulin dynamics while preserving $T U B B 3$ transcription in cells transfected with $\mathrm{FOXO} 3 a$ GFP and $A B C B 1$ siRNA. FOXO3 $a$ siRNA and $A B C B 1$-GFP were characterized as no-feedback and did not significantly induce any changes in the undermined $\mathrm{mt}$ tubulin levels after the treatment with PTX (Figure 7F); similar patterns were obtained in those without PTX treatment (Supplementary Figure 9). As reported previously, disrupted $T U B B 3$ functioning underlies impaired $\mathrm{mt}$ stability whereas missense mutations causing the loss of TUBB3 can induce increased $\mathrm{mt}$ stability $[50,51]$. This led us to hypothesize that the development of 5-FU cross-resistance in our PacR variant might have induced mutations in $T U B B 3$, thus causing its FOXO3a-directed negative regulation feedback 


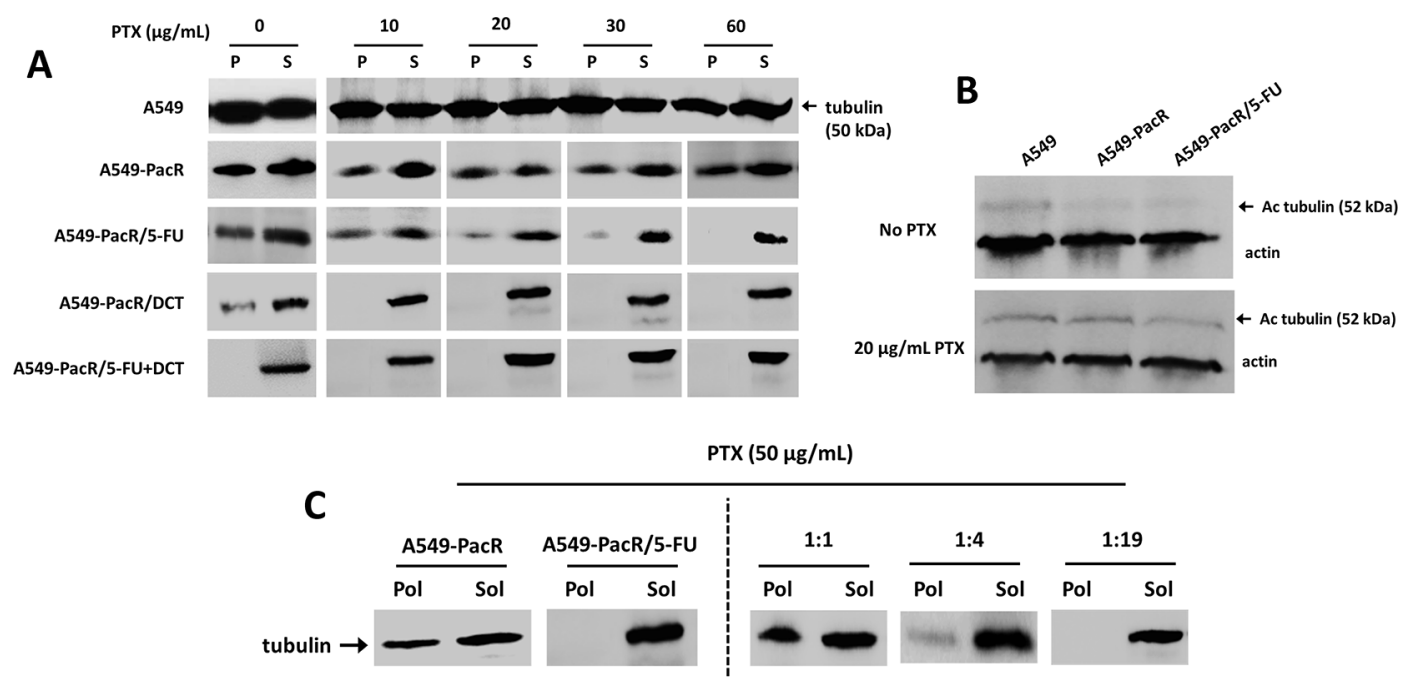

D

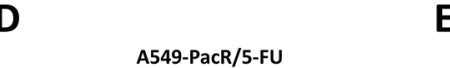

E

A FOXO3a-GFP $\rightarrow$ ABCB1-siRNA $\stackrel{\text { no feedback }}{\rightarrow}$ TUBB3

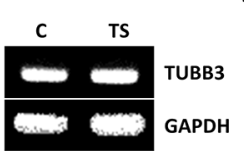

$\mathbf{F}$

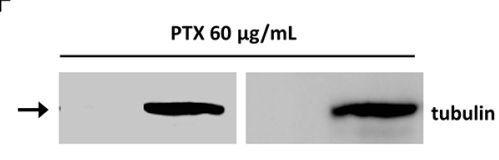

B FOXO3a-siRNA $\rightarrow$ ABCB1-siRNA $\stackrel{\text { reedback }}{\rightarrow}$ TUBB3

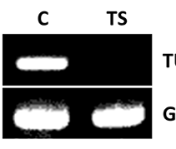

TUBB3

GAPDH
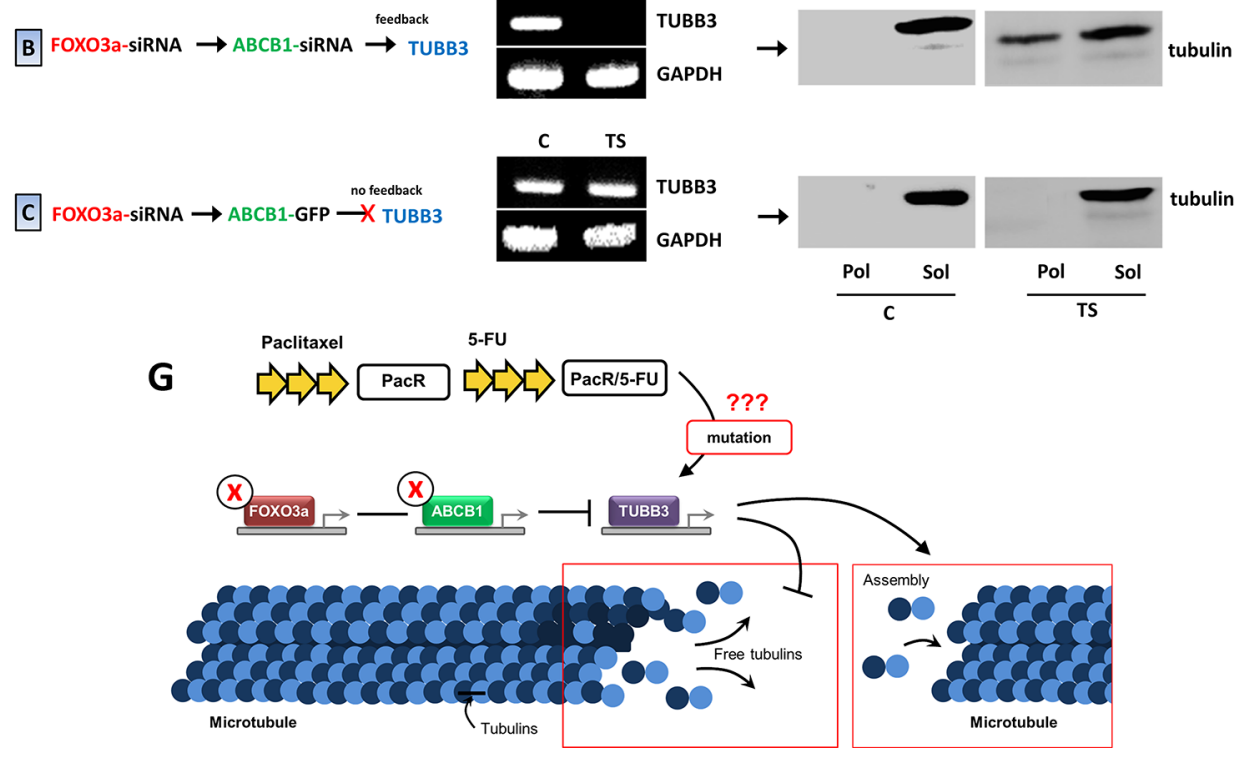

Figure 7: TUBB3 feedback inactivation reverses impaired microtubule stability in A549-PacR cells with developed transient multiple cross-resistance. (A) Microtubule stability in parental, PacR, and developed PacR phenotype cells with multiple transient cross-resistance. Cells were grown in the presence of indicated PTX concentrations for $18 \mathrm{hr}$. Following cell lysis, pellet (P) and the supernatant (S) protein fractions were separated by centrifugation and resolved on adjacent lanes by electrophoresis. Transferred filters were probed with tubulin antibody. (B) Acetylated tubulin status of parental, PacR, and developed PacR phenotype cells with multiple transient cross-resistance. Cells were grown in the absence or presence $20 \mathrm{nM}$ PTX for $18 \mathrm{hr}$, and the amount of acetylated tubulin was measured by immunoblotting using antibody specific to acetylated tubulin. (C) Mixing tubulin experiment. Indicated cells were harvested by adding hypotonic buffer with $50 \mu \mathrm{g} / \mathrm{mL}$ PTX for $15 \mathrm{~min}$. Whole cell lysate from PacR phenotype was added to that of developed PacR/5FU subline at different ratios as indicated, and incubated for an additional $10 \mathrm{~min}$. The polymerized (Pol) and soluble (Sol) protein fractions were processed as described in Materials and Methods. (D) Schematic diagram of transient gene transfection and/or siRNA silencing with respective TUBB3 feedback results used in $\mathrm{E}$ and $\mathrm{F}$ in A549-PacR/5-FU cells. (E) Confirmation of TUBB3 feedback gene expressions after transient transfection and/or siRNA silencing of indicated genes with $\mathrm{C}$ as control (respective empty vector and/or scramble siRNA) and TS as the transfection scheme shown in D. (F) Microtubule stability of A549-PacR/5-FU cells through tubulin polymerization after indicated transient gene and/or siRNA transfections. Cells were grown in the presence of $60 \mathrm{nM}$ PTX for $18 \mathrm{hr}$. The polymerized (Pol) and soluble (Sol) protein fractions were processed as in C. (G) Illustration of proposed mechanism behind the feedback response of TUBB3 to silencing of FOXO3a and ABCB1 in regulating microtubule stability in A549-PacR/5-FU cells. 
to increase mt stability, in part by increasing polymerized tubulin (Figure 7G). These findings indicate that incidence of the cross-resistance phenomenon in PTX-resistant cancers results in less mt stability associated with tubulins and their polymerization and that the regulation of $\mathrm{mt}$ dynamics can be coordinated directly by $T U B B 3$ genetic modifications, particularly by targeting $\mathrm{FOXO} 3 a$-mediated $A B C B 1$ activity.

\section{DISCUSSION}

PTX and its synthetic analogues have emerged as effective and clinically validated chemotherapeutic agents targeting the mt cytoskeleton with broad activity in solid tumors and hematological malignancies $[52,53]$. However, the occurrence of altered tubulin isotype expressions such as class III $\beta$-tubulin (encoded by TUBB3) is prominent in cancers receiving taxane-based therapy [54]. The factors contributing to genetic modifications of $T U B B 3$ have been poorly understood in the context of acquired drug resistance in several malignancies. Contrasting studies have been the center of controversy portraying tubulin point mutations at the PTX-binding sites conferring drug resistance. Previous reports noted disparities in the involvement of mutations in the class I $\beta$-tubulin isotype providing DNA sequencing of the fourth exon, which contains the paclitaxel-binding site, with primary drug resistance [54, 55]. This discrepancy was further supported with the results of the DNA sequence for K $\alpha 1$-tubulin, in which mutations were absent in both sensitive and resistant patients with invariable SNPs independently affecting patients' responses to PTX $[56,57]$. These clinical events shifted the focus to $\beta_{\mathrm{III}}$-tubulin-associated multiple genetic alterations in aggressive and drug refractory cancers because $\beta_{\mathrm{III}}$-tubulin has been mechanistically correlated with tubulin-binding agents (TBAs) although it is poorly understood in the context of drug resistance [58]. Accordingly, $\beta_{\mathrm{III}}$-tubulin has recently been classified as a biomarker for the onset of PTX-specific relapse for some cancer types. Thus, there is urgency in identifying molecular signatures that result in the modification of $\beta_{\mathrm{III}}$-tubulin at the transcriptional level in PTX-resistant cancers to accelerate the design of MDR reversal agents.

The present study demonstrates that $T U B B 3$ transcription can be controlled by $F O X O 3 a$-mediated $A B C B 1$ regulation and can subsequently promote the profusion of multiple cross-resistance and govern the tumor progression of PTX-resistant cancers. In a panel of normal and tumor cells that were primarily derived from the lung and prostate, we found that P-gp-associated drugresistant (PacR and GefR) cancer cells express higher TUBB3 and FOXO3a levels compared to drug-sensitive normal cells. Notably, we determined that our developed PTX-resistant cancer cells display cross-resistance to a variety of chemically different drugs including 5-FU, CIS and the PTX-analogue DCT. This occurrence led us to develop a transient cellular model of this cross-resistance.
The development of transient cross-resistance to drugs that are chemically different from PTX induced regulation in $F O X O 3 a$ and $T U B B 3$ endogenous expressions, encouraged escape from etoposide- and verapamil-induced cell death and was highly associated with P-gp hyperactivation. In support, we found regulated apoptotic signals and escalated intracellular ATP levels, which demonstrate a complementary mechanism by which MDR acquisition is associated with a drug response. Furthermore, druginduced activation of $F O X O 3 a$ up-regulates $\mathrm{P}-\mathrm{gp} / A B C B 1$ expression at gene promoter levels, which promotes cell death regulation and increases cell survival $[55,59]$. We currently lack experimental evidence on the genetic drivers that specify the augmentation of chemically different acquired drug cross-resistance in tumors that developed prior to first-line acquired drug resistance, which is a well-known characteristic of MDR aggression. Here, to address this particular issue and to shed light on the onset of multiplicity of cross-resistance defining MDR, we examined the influence of $F O X O 3 a$-regulated $A B C B 1$ to $T U B B 3$ feedback control, as suspected from our preliminary findings. We found that transient $T U B B 3$ activation, through $A B C B 1$, in response to the stimulation of $F O X O 3 a$ expression, significantly contributes to the cross-resistance of the PTX-resistant cell population and consequently limits the efficacy of both agents where cancer cells have developed multiple resistance. Mechanistic studies clearly demonstrate that the observed TUBB3 feedback control was physiologically, at least in part, amended by the ubiquitin-proteasome system engaged in the ubiquitin degradation pathway because the proteasome inhibitor upregulated $\beta_{\mathrm{III}}$-tubulin expression. Further, we found that increased polyubiquitination of TUBB3 was correlated with $\mathrm{FOXO} 3 a$ silencing in 5-FU cross-resistant PacR cancer cells which reflects a strong transcriptional feedback control of $T U B B 3$. The role of the ubiquitin-proteasome system in $\mathrm{mt}$ polymerization in cells has been previously described but remains underscored because malfunctioning of this system has been implicated in a variety of diseases $[60,61]$. However, in our in vitro model of acquired PTX resistance and 5-FU cross-resistance, the observed systemic polyubiquitination of $\beta_{\mathrm{III}}$-tubulin appeared to support previous findings on the role of specific ubiquitin substrates essential for tumor drug resistance [62].

In assessing the extent by which $\mathrm{FOXO} 3 \mathrm{a}$ regulates $A B C B 1$ transcription, we evaluated the methylation profiles of $A B C B 1$ promoter boxes deemed essential for P-gp activation and drug efflux pump hyperactivity conferring MDR. Of note, the transient overexpression of $\mathrm{FOXO3a}$ marginally promoted $A B C B 1$ methylation at the $-50 \mathrm{GC}$ and -110GC boxes, which are highly relevant binding sites for $A B C B 1$ substrates. PTX and 5-FU-mediated drug-induced methylation was also observed as confirmed by COBRA at the $\mathrm{CpG}$ site of the Inr region of $A B C B 1$, which showed increased DNA methylation. This finding appears to be critical in urging 5-FU cross-resistance in PTX-resistant cancers $[63,64]$.Therefore, the regulatory effects of 
FOXO3a on P-gp control add another layer of complexity to the role of $F O X O$ transcription factors in drug resistance and provide an understanding for conflicting activities in between. We identified the involvement of the PI3K/ Akt pathway, a critical regulator of $F O X O$ transcription factors, in this FOXO3a-directed regulation of P-gp at the protein expression level. Our results also underscore the association of these FOXO effectors, showing regulated levels of phospho-Akt and p27/Kip1 in FOXO3a overexpressing cells, which influence the control of P-gp and $\beta_{\mathrm{III}}$-tubulin. Although the regulatory activity of these signals in several drug-resistant models derived from colon and breast cancers has been reported $[65,66]$, this is the first study to reflect these associations in a MDR model stipulating 5-FU cross-resistance in PTX-resistant cancer cells. We also demonstrated a doxorubicin-induced increase in $\mathrm{FOXO} 3$ a methylation at arginine residues and increased FOXO3a translocation from the nucleus to the cytoplasm, which sheds light on how $\mathrm{FOXO} 3$ a regulates $A B C B 1$. Interestingly, complimentary activation of MRP1

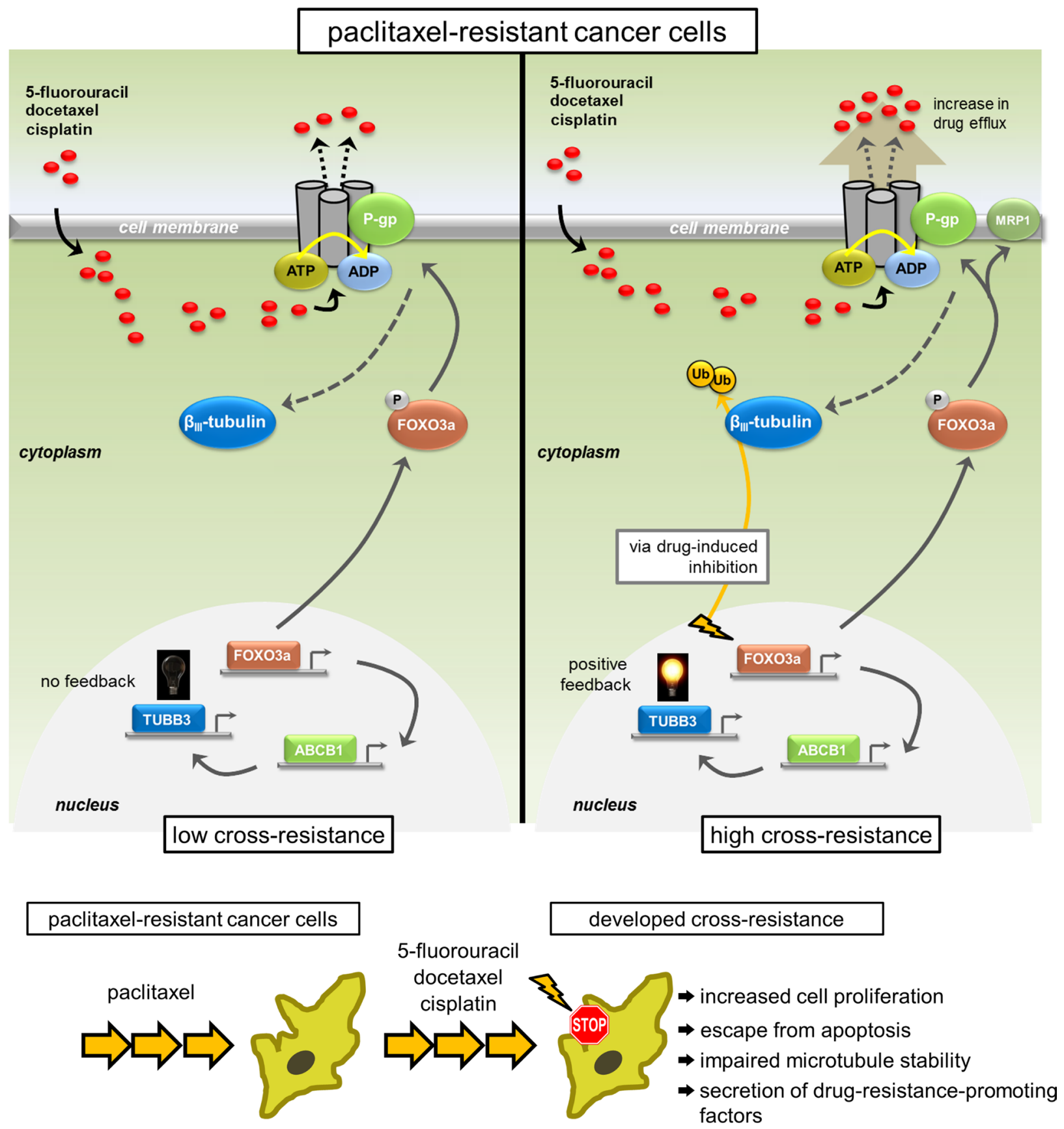

Figure 8: Model representation of the feedback control of TUBB3 via FOXO3a-mediated ABCB1 regulation inducing multiplicity in acquired cross-drug resistance. Multiplicity of acquired cross-resistance to structurally different drugs in cancer cells selected for taxane resistance is associated with feedback control of TUBB3 through FOXO3a-mediated ABCB1 regulation inducing hyperfunctional P-gp-associated drug efflux and escape from potential inhibition. 
has been observed in $\mathrm{FOXO3a}$ overexpressing cells, depicting that the regulation of $\mathrm{P}$-gp amended by $\mathrm{FOXO3a}$ influences MRP1 as an adjoining factor in conferring cross-resistance in PTX-resistant cancer cells.

The acquisition of PTX resistance is profoundly associated with a more aggressive and superinvasive phenotype both in vitro and in vivo $[67,68]$. Although highly associated with $\mathrm{P}-\mathrm{gp} / A B C B 1$ hyperactivation, $\mathrm{P}$-gp inhibitors are often ineffective and toxic at the doses required to suppress P-gp function in the clinic. In addition, PTX relapsed tumors rapidly develop MDR [69]. Our findings also indicate the contribution of secreted signals of PTX-resistant cancer cells with 5-FU cross-resistance to the outgrowth and regulation of $F O X O 3 a$-mediated $A B C B 1$ transcription, leading to a drug transporter efflux increase. Because these secretomes are unknown, we are not able to directly assess the interaction with P-gp. Despite this, we demonstrate that controlling the feedback of TUBB3 predicts P-gp-mediated efflux function influenced by complex drugresistant secretomes in vitro. Furthermore, 5-FU crossresistant PacR cancer cells display increased EMT associated with P-gp, which can be repressed by transient silencing of TUBB3. Notably, the knockdown of TUBB3 resulted in the attenuation of PacR/5-FU and PacR/CIS cancer cell-induced tumors in vivo associated with regulated levels of Akt and VEGF. Our study identifies that the response of $T U B B 3$ from $F O X O 3 a$-regulated $A B C B 1$ is a critical feedback mechanism to genetically identify cross-resistance in PTXresistant cancers and its tumor progression.

Dysfunction in $\mathrm{mt}$ stability and tubulin polymerization is associated with PTX resistance in several malignancies [70]. These particular underpinnings drove us to determine the status of $\mathrm{mt}$ dynamics in our PTX-resistant cancer cells with a transient crossresistance model. In particular, we found that impaired mt stability was correlated with the acquisition of the PacR, PacR/5-FU, PacR/DCT, and PacR/5-FU+DCT phenotypes. The lower acetylation level of tubulin in these models compared to the parental phenotype confirms irregularity in $\mathrm{mt}$ dynamics. Interestingly, we found complete attenuation of polymerized tubulin in PacR/5FU cells compared to PacR cells with higher tubulin polymerization. Furthermore, we found that transiently silencing $T U B B 3$ reversed the impaired mt stability in PacR/5-FU cells. Finally, the most significant conclusion of our study is that inducing $\mathrm{FOXO3a}$ activation mediates an upsurge in $A B C B 1$ transcription and P-gp function and collectively controls the $T U B B 3$ gene response to confer multiplicity in cross-resistance to chemically different drugs in PTX-resistant cancer cells (Figure 8). Our study opens avenues for understanding how PTXresistant cancers develop MDR and subsequently develop metastatic tumors. Our work also provides a rationale for manipulating $T U B B 3 / \beta_{\mathrm{III}}$-tubulin as a biomarker not just for PTX-resistant cancers but also for cross-resistance to a broad class of drugs.

\section{MATERIALS AND METHODS}

\section{Reagents}

DMEM, DMEM High Glucose, RPMI-1640 medium, M199, FBS, FCS, DPBS, antibiotic-antimycotic solution, trypsin-EDTA, TRI reagent, apoptosis kit with FITC annexin V and PI, Lipofectamine 3000 and PLUS reagents, Oligofectamine, and Opti-MEM Reduced Serum medium were purchased from Invitrogen (Grand Island, NY). siLentFect RNAi reagents were purchased from Bio-Rad (Hercules, CA). TCA reagent, MTT dye, PI, RNase A, crystal violet, sapphire 700, NAC, Rho-123 dye, BrdU, mouse anti-BrdU peroxidase, anti-tubulin, anti-acetylated tubulin, anti-actin, and HRP-conjugated secondary antibodies were purchased from Sigma-Aldrich (St. Louis, MO). Rabbit anti- $\beta_{\mathrm{III}}$-tubulin, anti-p27/Kip1, anti-vimentin, anti-VEGF, rat anti-MRP1, mouse antiP-gp, and anti-dimethyl arginine were purchased from Abcam (Cambridge, UK). Rabbit anti-FOXO3a, antiphospho-FOXO3a (ser318/321), anti-Akt, anti-phosphoAkt (ser473), anti-cyclin D1, anti-TCF8/ZEB1, anti-Ecadherin, anti-Snail, anti- $\beta$-catenin, and anti-myc-tag were purchased from Cell Signaling Technology (Danvers, MA). Mouse anti-phospho-ERK (Tyr204), anti-IgG, antic-myc, rabbit anti-IкB- $\alpha$, anti-cyclin A, anti-cyclin E, and anti-Rb, were purchased from Santa Cruz Biotechnology (Santa Cruz, CA). Gene-specific primers for real-time RT- and methylation-specific PCRs and ELISA were synthesized; and gene-specific plasmids and vectors were synthesized from Origene Technologies (Rockville, MD) and Bioneer (Daejeon, Korea). The Reverse Transcription, Pgp-Glo Assay Systems, and DeadEnd Colorimetric and Fluorometric TUNEL System kits were purchased from Promega (Madison, MA). The ABCB1 PREDEASY ATPase kit was purchased from Solvo Biotechnology (Szeged, Hungary). The EnzyLight ATP Assay Kit was purchased from BioAssay Systems (Hayward, CA). Protein G sepharose beads and ECL Plus Western blotting kits were purchased from GE Healthcare (Munich, Germany).

\section{Compounds}

Paclitaxel, 5-fluorouracil, cisplatin verapamil, and etoposide were purchased from Sigma-Aldrich. Docetaxel was purchased from LC Laboratories (Woburn, MA). MG132 was purchased from Calbiochem (San Diego, CA). Doxorubicin, gefitinib, and LY294002 were purchased from Selleck Chemicals (Houston, TX). All drugs used have $>99 \%$ purity identified through 
high-performance liquid chromatography and made commercially available.

\section{Cell culture}

The human normal prostate (RWPE-1), normal lung (L132, MRC-5), prostate cancer (PC-3), and lung cancer (H292) cell lines were obtained from the Korean Cell Line Bank (Seoul, Korea). The human lung cancer (A549), embryonic kidney (HEK293), and umbilical vein endothelial (HUVEC) cell lines were obtained from the American Type Culture Collection (Manassas, VA). Every 6 months, all cell lines were tested for mycoplasma contamination using the mycoplasma PCR detection kit (Intron Biotechnology, Sungnam, Korea). Cells were grown in medium (K-SFM for RWPE-1; DMEM for L132, MRC-5, and HEK293; RPMI-1640 for A549, PC-3, and H292 cells) supplemented with 10\% FBS and antibioticsantimycotics (100 units/mL penicillin G sodium, $100 \mathrm{mg} / \mathrm{ml}$ streptomycin, and $250 \mathrm{ng} / \mathrm{ml}$ amphotericin B [PSF]). HUVEC cells were grown in M199 medium with 20\% HIFBS, $20 \mu \mathrm{g} / \mathrm{ml}$ ECGS, and $50 \mu \mathrm{g} / \mathrm{mL}$ heparin. All cells were cultured at $37^{\circ} \mathrm{C}$ and $5 \% \mathrm{CO}_{2}$ in a humidified atmosphere.

\section{Establishment of drug resistant cell lines and transient cross-resistant phenotype}

Paclitaxel-resistant A549 (A549-PacR), PC-3 (PC-3PacR), and gefitinib-resistant H292 (H292-GefR) cells were originally developed by our team $[71,72]$ derived from their respective parental phenotype through continuous exposure to gradually increasing concentrations of the drug for $>12$ months maintaining continuous growth and fine parental-like morphology. Drug resistant cells were maintained in medium containing low-dose drug and were found to have $>200$ resistance fold. PTX-resistant (A549and PC-3-PacR) cells were developed to have transient cross-resistance to 5-fluorouracil (PacR/5-FU), docetaxel (PacR/DCT), and cisplatin (PacR/CIS) by culturing PTXresistant cells in serum-rich (20-25\% FBS) medium for 3 days followed by exposure to gradually increasing concentrations of structurally-different drugs for 12 days (5-FU, 2.5-75 $\mu \mathrm{M}$; DCT, 10-60 nM; CIS, 2.5-50 $\mu \mathrm{M}$ ) reaching a high-dose were cross-resistant cells survived and were selected in a serum-starving medium $(20 \%, 10 \%, 5 \%$, $2 \%, 0 \% \mathrm{FBS}$ intervals following subculture). After crossresistance selection, cells were exposed to low tolerating dose of drugs (5-FU, 5-30 $\mu \mathrm{M}$; DCT, 25-60 nM; CIS, $5-25 \mu \mathrm{M})$ for 20 days in a serum-enriching medium $(0 \%$, $5 \%, 10 \%, 20 \%$ FBS intervals following subculture). Cells were subcultured for every 48-56 hr cycle. Apoptotic cell morphology and P-gp and MRP1 MDR-marker protein expression check-ups were conducted at days 7 and 19 of the $>35$ days of transient cross-resistant phenotype development (Supplementary Figure 6). PTX-resistant cells with confirmed cross-resistance were maintained in medium containing low-dose drug (1/25-1/30 of their respective $\left.\mathrm{IC}_{50} \mathrm{~s}\right)$. All drug-resistant subline cells were cultured in medium in the same formulation and condition as with their parental phenotype.

\section{RNA extraction, real-time RT-PCR, methylation- specific PCR, and COBRA}

RNA extraction and real-time RT-PCR were performed as described previously [71]. Genomic DNA isolation, bisulphite treatment of DNA, and methylationspecific PCR were carried out as described previously $[73,74]$. Bisulphite DNA modification, primer design for and combined bisulphate restriction analysis (COBRA) of ABCB1 were performed as described previously [74]. All primer sequences are listed in Supplementary Table 1.

\section{Western blot analysis and immunoprecipitation}

Preparation of lysates, protein quantification, SDS-PAGE, and Western blot analysis were carried out as described previously [76]. Immunoprecipitation was performed as described previously [76].

\section{Plasmids, gene transient transfections, and RNAi}

For ABCB1 overexpression studies, cells were dual transfected with pCMV6-AC-GFP (empty vector) and pCMV6-AC-ABCB1 (GFP-tagged ABCB1) using Lipofectamine 3000 (Life Technologies). The wild type ABCB1 expression vector consists of full-length ABCB1 (MDR1) cDNA within the pCMV6 mammalian expression vector (Origene Technologies). For FOXO3a overexpression studies, cells were dual transfected with pEGFP-N1 (empty vector) and pEGFP-N1-FOXO3a using Lipofectamine 3000. The fusion GFP-tagged FOXO3a-WT encoding vector was constructed by subcloning the full-length FOXO3a cDNA (Clontech, Palo Alto, CA). Gene-specific methods used for transient transfections were described previously [78, 79]. For ABCB1 silencing, cells were transfected with scramble siRNA (FITC-conjugate) or human-specific ABCB1 (MDR1) siRNA duplexes (Santa Cruz Biotechnology) using Lipofectamine 3000 [80]. For FOXO3a silencing, cells were transfected with stealth scramble or FOXO3a siRNAs (Santa Cruz Biotechnology) using Lipofectamine 3000 [81]. For TUBB3 silencing, cells were transfected with scramble or TUBB3 siRNA oligos (Ambion, Austin, TX) using siLentFect (Bio-Rad) [82]. Transfectants were subjected to drug treatment and/or assays after $48 \mathrm{hr}$ of transfection. RNAi and transient gene transfection efficiencies and cell morphology are presented in Supplementary Figure 7. 


\section{Immunocytochemistry}

Immunofluorescences of cells were observed using Zeiss LSM 780 ApoTome microscope (Carl Zeiss, Jena, Germany). Fluorescence imaging and immunocytochemistry were performed as previously described [71].

\section{Cell proliferation and colony formation assays}

MTT assay was carried out to determine cell proliferation as described previously [73]. Colony formation assay using crystal violet or sapphire 700 staining was performed as described previously [83].

\section{Apoptosis, BrdU incorporation, and cell cycle assays}

Assessment of apoptotic cells using AnnexinV-FITC and PI double staining kit was performed as described previously [84]. BrdU incorporation assay and cell cycle analysis were performed as described previously [71]. All fluorescent events were acquired using a FACSCalibur equipped with CellQuest Pro software (BD Biosciences, San Jose, CA).

\section{ABCB1 and P-gp atpase activity, Rho-123 assay, and ATP quantification}

ATPase activity determination was carried out using ABCB1 PREDEASY ATPase kit and Pgp-Glo Assay System kit according to manufacturer's instructions (Promega and Solvo Biotechnology, respectively). Rho123 accumulation assay was carried out as described previously [71]. Determination of intracellular ATP content was performed using EnzyLight ATP Assay kit according to manufacturer's instructions (BioAssay Systems).

\section{Isolation of cytosolic and nuclear extracts}

Cells were harvested at $80 \%$ confluence through trypsination. Isolation of nuclei and cytosol was carried out using NE-PER Nuclear and Cytoplasmic Extraction Reagents (Pierce, Rockford, IL) following manufacturer's instructions.

\section{Cell migration, invasion, and soft agar assays}

Chemotaxis-induced migration and cell invasion assays were carried out in Boyden chamber wells with or without matrigel-based membrane as described previously [73]. Anchorage-independent growth was assessed in a two-layer agar system with final concentration of $0.8 \%$ for the bottom and $0.4 \%$ for the top agarose layers according to manufacturer's protocol (Millipore, Bedford, MA).
In vivo tumor xenograft model, tumor

immunohistochemistry, and ex vivo

biochemical analysis

All animal use and care followed the ethical guidelines of and approved by the Seoul National University Institutional Animal Care and Use Committee. 5-6 weeks old male (BALB/c-nu) athymic mice were purchased from Hyochang Science (Daegu, Korea). Viable cells were determined by trypan blue exclusion test and a total cell density of $3 \times 10^{7}$ from each group ( $n=2$ to 4$)$ were collected. Bulk cell suspensions were diluted in matrigel (1:1 mix ratio) and were injected subcutaneously into the upper and lower right and left flanks. All mice did not receive any drug treatment after injection. All mice were mercifully killed at day 35 and the tumor were removed, scaled, and subjected to further analysis. Immunohistochemistry of tumors, H\&E staining, and ex vivo biochemical analysis were performed as described previously [77]. TUNEL assay of paraffin-embedded tissues were carried out according to manufacturer's protocol using the DeadEnd TUNEL System kits (Promega).

\section{Microtubule stability assessment, tubulin polymerization and acetylated tubulin measurement}

Mt stability was assessed with slight modification as described previously [85]. Degree of tubulin polymerization, mixing experiment, and measurement of relative acetylated tubulin in cells were carried out as described previously [4].

\section{Software, statistics, and image acquisition}

Statistical analyses were assessed $(p<0.05)$ and performed using OriginPro 8.0 (OriginLab, Northampton, $\mathrm{MA}) . \mathrm{IC}_{50}$ values of all compounds and non-linear regression were calculated using the TableCurve 2D v5.01 (Systat Software Inc., San Jose, CA). Statistical evaluation were carried out using one-/two-way ANOVA with Bonferroni's multiple comparisons post-test and Student's $t$ test and $x^{2}$ test. GraphPad Prism 5.01 software was used to calculate the mean fluorescence intensity (MFI). Adobe Photoshop software was also used for image acquisition aid and only brightness and/or contrast of expression blots were simultaneously changed for all areas only if deemed necessary. All results were obtained from at least three independent experiments and most were biologically replicated. The data are presented as mean $\pm \mathrm{SD}$.

\section{ACKNOWLEDGMENTS}

We thank Song Yi Bae (College of Pharmacy, Seoul National University) for providing the H292-GefR cell line and for its culture maintenance. 


\section{CONFLICTS OF INTEREST}

The authors declare no conflicts of interest.

\section{GRANT SUPPORT}

This work was supported by a grant from procurement and development of biological resources funded by Ministry of Education Science and Technology of Korean government (2011-00499) and Basic Science Research Program through the National Research Foundation of Korea (NRF) funded by the Ministry of Education, Science and Technology (2013R1A1A2012389).

\section{Authors' contributions}

M.B.D.A. designed and performed the experiments, analyzed data, and wrote the initial draft of the manuscript. J.Y.H. provided assistance in the design of experiments, analysis of data, and edited the manuscript. M.V.A. provided assistance in the RNA and fluorescence experiments. J.S. provided, characterized, and maintained the PC-3 and PC-3-PacR cell lines. S.K.L. designed and supervised the experiments and edited the manuscript with contributions from all authors.

\section{REFERENCES}

1. Gottesman MM, Fojo T, Bates SE. Multidrug resistance in cancer: role of ATP-dependent transporters. Nat Rev Cancer. 2005; 2:48-58.

2. Higgins CF. Multiple molecular mechanisms for multidrug resistance transporters. Nature. 2007; 446:749-757.

3. Xiao H, Verdier-Pinard P, Fernandez-Fuentes N, Burd B, Angeletti R, Fiser A, Horwitz SB, Orr GA. Insights into the mechanism of microtubule stabilization by taxol. Proc Natl Acad Sci USA. 2006; 27:10166-10173.

4. Hari M, Loganzo F, Annable T, Tan X, Musto S, Morilla DB, Nettles JH, Snyder JP, Greenberger LM. Paclitaxel-resistant cells have a mutation in the paclitaxel-binding region of $\beta$-tubulin (Asp26Glu) and less stable microtubules. Mol Cancer Ther. 2006; 5:270-278.

5. Stengel S, Newman SP, Leese MP, Potter BVL, Reed MJ, Purohit A. Class III $\beta$-tubulin expression and in vitro resistance to microtubule targeting agents. $\mathrm{Br} \mathrm{J}$ Cancer. 2010; 102:316-324.

6. Bhat KMR, Setaluri V. Microtubule-associated proteins as targets in cancer chemotherapy. Clin Cancer Res. 2007; 13:2849-2854.

7. Orr GA, Verdier-Pinard P, McDaid H, Horwitz SB. Mechanisms of taxol resistance related to microtubules. Oncogene. 2003; 22:7280-7295.

8. Dumontet C, Jordan MA. Microtubule-binding agents: a dynamic field of cancer therapeutics. Nat Rev Drug Discov. 2010; 9:790-803.
9. Huzil JT, Chen K, Kurgan L, Tuszynski JA. The roles of $\beta$-tubulin mutations and isotype expression in acquired drug resistance. Cancer Inform. 2007; 3:159-181.

10. Gomes AR, Brosens JJ, Lam EWF. Resist or die: FOXO transcription factors determine the cellular response to chemotherapy. Cell Cycle. 2008; 7:3133-3136.

11. Hui RC, Francis RE, Guest SK, Costa JR, GomesAR, Myatt SS, Brosens JJ, Lam EWF. Doxorubicin activates FOXO3a to induce the expression of multidrug resistance gene ABCB1 (MDR1) in K562 leukemic cells. Mol Cancer Ther. 2008; 7:670-678.

12. Ho KK, Myatt SS, Lam EWF. Many forks in the path: cycling with FoxO. Oncogene. 2008; 27:2300-2311.

13. VanderWeele DJ, Zhou R, Rudin CM. Akt up-regulation increases resistance to microtubule-directed chemotherapeutic agents through mammalian target of rapamycin. Mol Cancer Ther. 2004; 3:1605-1613.

14. Fu Z, Tindall DJ. FOXOs, cancer and regulation of apoptosis. Oncogene. 2008; 27:2312-2319.

15. Sunters A, Madureira PA, Pomeranz KM, Aubert M, Brosens JJ, Cook SJ, Burgering BMT, Coombes C, Lam EWF. Paclitaxel-induced nuclear translocation of FOXO3a in breast cancer cells is mediated by c-Jun NH2-terminal kinase and Akt. Cancer Res. 2006; 66:212-220.

16. Shiota K, Yokomizo A, Kashiwagi E, Tada Y, Inokuchi J, Tatsugami K, Kuroiwa K, Uchiumi T, Seki N, Naito S. Foxo3a expression and acetylation regulate cancer cell growth and sensitivity to cisplatin. Cancer Sci. 2010; 101: 1171-1185.

17. Lam EWF, Brosens JJ, Gomes AR, Koo CY. Forkhead box proteins: tuning forks for transcriptional harmony. Nat Rev Cancer. 2013; 13:482-495.

18. Nestal de Moraes G, Bella L, Zona S, Burton MJ, Lam EWF. Insights into a critical role of the FOXO3a-FOXM1 axis in DNA damage response and genotoxic drug resistance. Curr Drug Targets. 2014 [Epub ahead of print].

19. Nechipurenko IV, Broihier HT. FoxO limits microtubule stability and is itself negatively regulated by microtubule disruption. J Cell Biol. 2012; 196:345-362.

20. Wang X, Wang Z, Chen Y, Huang X, Hu Y, Zhang R, Ho MS, Xue L. FoxO mediates APP-induced AICD-dependent cell death. Cell Death Dis. 2014; 5:e1233.

21. Zhao Y, Tindall DJ, Huang H. Modulation of androgen receptor by FOXA1 and FOXO1 factors in prostate cancer. Int J Biol Sci. 2014; 10: 614-619.

22. Liu P, Kumar IS, Brown S, Kannappan V, Tawari PE, Tang JZ, Jiang W, Armesilla AL, Darling JL, Wang W. Disulfiram targets cancer stem-like cells and reverses resistance and cross-resistance in acquired paclitaxel-resistant triple-negative breast cancer cells. Br J Cancer. 2013; 109:1876-1885.

23. Guo B, Villeneuve DJ, Hembruff SL, Kirwan AF, Blais DE, Bonin M, Parissenti AM. Cross-resistance studies of isogenic drug-resistant breast tumor cell lines support recent clinical evidence suggesting that sensitivity to paclitaxel may be strongly compromised by prior doxorubicin exposure. Breast Cancer Res Treat. 2004; 85:31-51. 
24. Kenicer J, Spears M, Lyttle N, Taylor KJ, Liao L, Cunningham CA, Lambros M, MacKay A, Yao C, ReisFilho J, Bartlett JM. Molecular characterisation of isogenic taxane resistant cell lines identify novel drivers of drug resistance. BMC Cancer. 2014; 14:762-771.

25. Seve P, Dumontet C. Is class III beta-tubulin a predictive factor in patients receiving tubulin-binding agents? Lancet Oncol. 2008; 9:168-175.

26. Shalli K, Brown I, Heys SD, Schofield AC. Alterations of beta-tubulin isotypes in breast cancer cells resistant to docetaxel. FASEB J. 2005; 19:1299-1301.

27. Savry A, Carre M, Berges R, Rovini A, Pobel I, Chacon C, Braguer D, Bourgarel-Rey V. Bcl-2-enhanced efficacy of microtubule-targeting chemotherapy through Bim overexpression: implications for cancer treatment. Neoplasia. 2013; 15:49-60.

28. Han CY, Cho KB, Choi HS, Han HK, Kang KW. Role of FoxO1 activation in MDR1 expression in adriamycinresistant breast cancer cells. Carcinogenesis. 2008; 29: 1837-1844.

29. Ajabnoor GMA, Crook T, Coley HM. Paclitaxel resistance is associated with switch from apoptotic to autophagic cell death in MCF-7 breast cancer cells. Cell Death Dis. 2012; 3:e260.

30. Yen TJ, Gay DA, Pachter S, Cleveland DW. Autoregulated changes in stability of olyribosome-bound beta-tubulin mRNAs are specified by the first 13 translated nucleotides. Mol Cell Biol. 1988; 8:1224-1235.

31. Bergstrom RA, Sinjoanu RC, Ferreira A. Agrin induced morphological and structural changes in growth cones of cultured hippocampal neurons. Neuroscience. 2007; 149:527-536.

32. Shibazaki M, Maesawa C, Akasaka K, Kasai S, Yasuhira S, Kanno K, Nakayama I, Sugiyama T, Wakabayasi G, Masuda T, Mori N. Transcriptional and post-transcriptional regulation of $\beta$ III-tubulin protein expression in relation with cell cycledependent regulation of tumor cells. Int J Oncol. 2012; 40:695-702.

33. MuggerudAA, Rønneberg JA, Wärnberg F, Botling J, Busato F, Jovanovic J, Solvang H, Bukholm I, Børresen-Dale AL, Kristensen VN, Sorlie T, Tost J. Frequent aberrant DNA methylation of ABCB1, FOXC1, PPP2R2B and PTEN in ductal carcinoma in situ and early invasive breast cancer. Breast Cancer Res. 2010; 12:R3.

34. Shang Y, Zhang Z, Liu Z, Feng B, Ren G, Li K, Zhou L, Sun Y, Li M, Zhou J, An Y, Wu K, Nie Y, et al. miR-508-5p regulates multidrug resistance of gastric cancer by targeting ABCB1 and ZNRD1. Oncogene. 2014; 33:3267-3276.

35. El-Osta A, Kantharidis P, Zalcberg JR, Wolffe AP. Precipitous release of methyl-CpG binding protein 2 and histone deacetylase 1 from the methylated human multidrug resistance gene (MDR1) on activation. Mol Cell Biol. 2002; 22:1844-1857.
36. Fernandez de Mattos S, Essafi A, Soeiro I, Pietersen AM, Birkenkamp KU, Edwards CS, Martino A, Nelson BH, Francis JM, Jones MC, Brosens JJ, Coffer PJ, Lam EWF. FoxO3a and BCR-ABL regulate cyclin D2 transcription through a STAT5/BCL6-dependent mechanism. Mol Cell Biol. 2004; 24:10058-10071.

37. Ho KK, McGuire VA, Koo CY, Muir KW, de Olano N, Maifoshie E, Kelly DJ, McGovern UB, Monteiro LJ, Gomes AR, Nebreda AR, Campbell DG, Arthur JS, et al. Phosphorylation of FOXO3a on Ser-7 by $\mathrm{p} 38$ promotes its nuclear localization in response to doxorubicin. J Biol Chem. 2012; 287:1545-1555.

38. Sherbakova EA, Stromskaia TP, Rybalkina EYu, Kalita OV, Stavrovskaia AA. Role of PTEN protein in multidrug resistance of prostate cancer cells. Mol Biol. 2008; 42: 487-493.

39. Wilson TR, Fridlyand J, Yan Y, Penuel E, Burton L, Chan E, Peng J, Lin E, Wang Y, Sosman J, Ribas A, Li J, Moffat J, et al. Widespread potential for growth-factor-driven resistance to anticancer kinase inhibitors. Nature. 2012; 487:505-509.

40. Villanueva J, Herlyn M. Melanoma and the tumor microenvironment. Curr Oncol Rep. 2008; 10:439-446.

41. ObenaufAC, Zou Y, JiAL, Vanharanta S, Shu W, Shi H, Kong X, Bosenberg MC, Wiesner T, Rosen N, Lo RS, Massague J. Therapy-induced tumour secretomes promote resistance and tumour progression. Nature. 2015; 16:368-372.

42. Shiota M, Yokomizo A, Kashiwagi E, Tada Y, Inokuchi J, Tatsugami K, Uchiumi T, Seki N, Naito S. Foxo3a expression and acetylation regulate cancer cell growth and sensitivity to cisplatin. Cancer Sci 2010; 101:1177-1185.

43. Stordal B, Hamon M, McEneaney V, Roche S, Gillet J-P, O'Leary JJ, Gottesman M, Clynes M. Resistance to paclitaxel ina cisplatin-resistant ovarian cancer cell line is mediated by P-glycoprotein. PLoS ONE 2012; 7:e40717.

44. Miyamoto K, Araki KY, Naka K, Arai F, Takubo K, Yamazaki S, Matsuoka S, Miyamoto T, Ito K, Ohmura M, Chen C, Hosokawa $\mathrm{K}$, et al. Foxo3a is essential for maintenance of the hematopoietic stem cell pool. Cell Stem Cell 2007; 1:101-112.

45. Kim JJ, Yin B, Christudass CS, Terada N, Rajagopalan K, Fabry B, Lee DY, Shiraishi T, Getzenberg RH, Veltri RW, An SS, Mooney SM. Acquisition of paclitaxel resistance is associated with a more aggressive and invasive phenotype in prostate cancer. J Cell Biochem. 2013; 114:1286-1293.

46. Kadoyama K, Kunwahara A, Yamamori M, Brown JB, Sakaeda T, Okuno Y. Hypersensitivity reactions to anticancer agents: data mining of the public version of the FDA adverse event reporting system, AERS. J. Exp. Clin Cancer Res. 2011; 30:93-98.

47. Wellner U, Schubert J, Burk UC, Schmalhofer O, Zhu F, Sonntag A, Waldvogel B, Vannier C, Darling D, zur Hausen A, Brunton VG, Morton J, Sansom O, et al. The EMT-activator 
ZEB1 promotes tumorigenicity by repressing stemnessinhibiting microRNAs. Nat Cell Biol. 2009; 11:1487-1495.

48. Akiyama K, Ohga N, Hida Y, Kawamoto T, Sadamoto Y, Ishikawa S, Maishi N, Akino T, Kondoh M, Matsuda A, Inoue N, Shindoh M, Hida K. Tumor endothelial cells acquire drug resistance by MDR1 up-regulation via VEGF signaling in tumor microenvironment. Am J Pathol. 2012; 180:1283-1293.

49. Verma K, Ramanathan K. Investigation of paclitaxel resistant $\mathrm{R} 306 \mathrm{C}$ mutation in $\beta$-tubulin-a computational approach. J Cell Biochem. 2015; 116:1318-1324.

50. Tischfield MA, Baris HN, Wu C, Rudolph G, Maldergem LV, He W, Chan W-M, Andrews C, Demer JL, Robertson RL, Mackey DA, Ruddle JB, Bird TD, et al. Human TUBB3 mutations perturb microtubule dynamics, kinesin interactions, and axon guidance. Cell. 2010; 140:74-87.

51. Singh KK, Tsai L-H. MicroTUB(B3)ules and brain development. Cell. 2010; 140:30-32.

52. Baas PW, Ahmad FJ. Beyond taxol: microtubule-based treatment of disease and injury of the nervous system. Brain. 2013; 136:2937-2951.

53. Palazzo A, Ackerman B, Gundersen GG. Cell biology: tubulin acetylation and cell motility. Nature. 2003; 421: 230.

54. Patel N, Chatterjee SK, Vrbanac V, Chung I, Mu CJ, Olsen RR, Waghorne C, Zetter BR. Rescue of paclitaxel sensitivity by repression of Prohibitin1 in drug-resistant cancer cells. Proc Natl Acad Sci USA. 2010; 107:2503-2508.

55. Weaver BA. How taxol/paclitaxel kills cancer cells. Mol Biol Cell. 2014; 25:2677-2681.

56. Mariani M, Shahabi S, Sieber S, Scambia G, Ferlini C. Class III $\beta$-tubulin (TUBB3): more than a biomarker in solid tumors? Curr Mol Med. 2011; 11:726-731.

57. Sale S, Sung R, Shen P, Yu K, Wang Y, Duran GE, Kim JH, Fojo T, Oefner PJ, Sikic BI. Conservation of the class I betatubulin gene in human populations and lack of mutations in lung cancers and paclitaxel-resistant ovarian cancers. Mol Cancer Ther. 2002; 1:215-225.

58. Martello LA, Verdier-PinardP, Shen HJ, He L, Torres K, Orr GA, Horwitz SB. Elevated levels of microtubule destabilizing factors in a Taxol-resistant/dependent A549 cell line with an alpha-tubulin mutation. Cancer Res. 2003; 63:1207-1213.

59. Katsetos CD, Draberova E, Legido A, Dumontet C, Draber P. Tubulin targets in the pathobiology and therapy of glioblastoma multiforme. I. Class III beta-tubulin. J Cell Physiol. 2009; 221:505-513.

60. Lin L, Hron JD, Peng SL. Regulation of NF-kappaB, Th activation, and autoinflammation by the forkhead transcription factor Foxo3a. Immunity. 2004; 21:203-213.

61. Touil Y, Zuliani T, Wolowczuk I, Kuranda K, Prochazkova J, Andrieux J, Le Roy H, Mortier L, Vandomme J, Jouy N, Masselot B, Segard P, Quesnel B, et al. The PI3K/ AKT signaling pathway controls the quiescence of the low-Rhodamine123-retention cell compartment enriched for melanoma stem cell activity. Stem Cells. 2013; 31: 641-651.
62. Lecker SH, Goldberg AL, Mitch WE. Protein degradation by the ubiquitin-proteasome pathway in normal and disease states. J Am Soc Nephrol. 2006; 17:1807-1819.

63. Soucy TA, Smith PG, Milhollen MA, Berger AJ, Gavin JM, Adhikari S, Brownell JE, Burke KE, Cardin DP, Critchley S, Cullis CA, Doucette A, Garnsey JJ, et al. An inhibitor of NEDD8-activating enzyme as a new approach to treat cancer. Nature. 2009; 458:732-736.

64. Landis-Piwowar KR, Milacic V, Chen D, Yang H, Zhao Y, Chan TH, Yan B, Dou QP. The proteasome as a potential target for novel anticancer drugs and chemosensitizers. Drug Resist Updat. 2006; 9:263-273.

65. Hong L, Han Y, Zhang H, Zhao Q, Wu K, Fan D. Drug resistance-related miRNAs in hepatocellular cancer. Expert Rev Gastroenterol Hepatol. 2014; 8:283-288.

66. Tahara T, Arisawa T, Shibata T, Yamashita H, Yoshioka D, Hirata I. Effect of promoter methylation of multidrug resistance 1 (MDR1) gene in gastric carcinogenesis. Anticancer Res. 2009; 29:337-341.

67. Tenbaum SP, Ordonez-Moran P, Puig I, Chicote I, Arques O, Landolfi S, Fernandez Y, Herance JR, Gispert JD, Mendizabal L, Aguilar S, Ramon y Cajal S, Schwartz S Jr, et al. $\beta$-catenin confers resistance to PI3K and AKT inhibitors and subverts FOXO3a to promote metastasis in colon cancer. Nat Med. 2012; 18:892-901.

68. Chen J, Gomes AR, Monteiro LJ, Wong SY, Wu LH, Ng TT, Karadedou CT, Millour J, Ip YC, Cheung YN, Sunters A, Chan KY, Lam EWF, et al. Constitutively nuclear FOXO3a localization predicts poor survival and promotes Akt phosphorylation in breast cancer. PLoS ONE. 2010; 5:e12293.

69. Glynn SA, Gammell P, Heenan M, O’Connor R, Liang Y, Keenan J, Clynes M. A new superinvasive in vitro phenotype induced by selection of human breast carcinoma cells with the chemotherapeutic drugs paclitaxel and doxorubicin. Br J Cancer. 2004; 91:1800-1807.

70. Dong Y, Stephens C, Walpole C, Swedberg JE, Boyle GM, Parsons PG, McGuckin MA, Harris JM, Clements JA. Paclitaxel resistance and multicellular spheroid formation are induced by kallikrein-related peptidase 4 in serous ovarian cancer cells in an ascites mimicking microenvironment. PLoS ONE. 2013; 8:e57056.

71. Aldonza MBD, Hong JY, Bae SY, Song J, Kim WK, Oh J, Shin Y, Lee SH, Lee SK. Suppression of MAPK signaling and reversal of mTOR-dependent MDR1-associated multidrug resistance by $21 \alpha$-methylmelianodiol in lung cancer cells. PLoS ONE. 2015; 10:e127841

72. Bae SY, Hong JY, Lee HJ, Park HJ, Lee SK. Targeting the degradation of AXL receptor tyrosine kinase to overcome resistance in gefitinib-resistant non-small cell lung cancer. Oncotarget. 2015; 6:10146-10160. doi: 10.18632/ oncotarget.3382.

73. Na SS, Aldonza MB, Sung HJ, Kim Y, Son YS, Cho S, Cho JY. Stanniocalcin-2 (STC2): a potential lung cancer biomarker promotes lung cancer metastasis and progression. Biochim Biophys Acta. 2015; 1854:668-676. 
74. El-Khoury V, Breuzard G, Fourre N, Dufer J. The histone deacetylase inhibitor trichostatin A downregulates human MDR1 (ABCB1) gene expression by a transcriptiondependent mechanism in a drug-resistant small cell lung carcinoma cell line model. Br J Cancer. 2007; 97:562-573.

75. Garcia-Manero G, Bueso-Ramos C, Daniel J, Williamson J, Kantarjian HM, Issa JP. DNA methylation patterns at relapse in adult acute lymphocytic leukemia. Clin Cancer Res. 2002; 8:1897-1903.

76. Ahn JM, Sung HJ, Yoon YH, Kim BG, Yang WS, Lee C, Park HM, Kim BJ, Kim BG, Lee SY, An HJ, Cho JY. Integrated glycoproteomics demonstrates fucosylated serum paraoxonase 1 alterations in small cell lung cancer. Mol Cell Proteomics. 2014; 13:30.48.

77. Song J, Kwon Y, Kim S, Lee SK. Antitumor activity of phenanthroindolizidine alkaloids is associated with negative regulation of met endosomal signaling in renal cancer cells. Chem Biol. 2015; 22:504-515.

78. Riganti C, Salaroglio IC, Caldera V, Campia I, Kopecka J, Mellai M, Annovazzi L, Bosia A, Ghigo D, Schiffer D. Temozolomide downregulates P-glycoprotein expression in glioblastoma stem cells by interfering with the Wnt3a/ glycogen synthase-3 kinase/ $\beta$-catenin pathway. Neuro Oncol. 2013; 15:1502-1517.

79. Singh A, Ye M, Bucur O, Zhu S, Santos MT, Rabinovitz I, Wei W, Gao D, Hahn WC, Khosravi-Far R. Protein phosphatase $2 \mathrm{~A}$ reactivates $\mathrm{FOXO}$ a through a dynamic interplay with 14-3-3 and AKT. Mol Biol Cell. 2010; 21:1140-1152.

80. Wen X, Gibson CJ, Yang I, Buckley B, Goedken MJ, Richardson JR, Aleksunes LM. MDR1 transporter protects against paraquat-induced toxicity in human and mouse proximal tubule cells. Toxicol Sci. 2014; 141:475-483.

81. Luo H, Yang Y, Duan J, Wu P, Jiang Q, Xu C. PTEN-regulated $\mathrm{AKT} / \mathrm{FoxO} \mathrm{a} / \mathrm{Bim}$ signaling contributes to reactive oxygen species-mediated apoptosis in selenite-treated colorectal cancer cells. Cell Death Dis. 2013; 4:e481.

82. Narvi E, Jaakkola K, Winsel S, Oetken-Linholm C, Halonen P, Kallio L, Kallio MJ. Altered TUBB3 expression contributes to the epothilone response of mitotic cells. Br J Cancer. 2013; 108:82-90.

83. Lee HJ, Zhuang G, Cao Y, Du P, Kim HJ, Settleman J. Drug resistance via feedback activation of Stat3 in oncogeneaddicted cancer cells. Cancer Cell. 2014; 26:207-221.

84. Kim GD, Oh J, Park HJ, Bae K, Lee SK. Magnolol inhibits angiogenesis by regulating ROS-mediated apoptosis and the $\mathrm{PI} 3 \mathrm{~K} / \mathrm{AKT} / \mathrm{mTOR}$ signaling pathway in $\mathrm{mES} / \mathrm{EB}$-derived endothelial-like cells. Int J Oncol. 2013; 43:600-610.

85. Bhattacharya R, Cabral F. A ubiquitous $\beta$-tubulin disrupts microtubule assembly and inhibits cell proliferation. Mol Biol Cell. 2004; 15:3123-3131. 